\title{
La presencia de los jesuitas en Colonia del Sacramento
}

The presence of the Jesuits in

Colonia del Sacramento

Carlos A. Page*

\section{Resumen}

La permanencia de los jesuitas portugueses en Colonia del Sacramento se prolongó por poco más de medio siglo, soportando las adversidades a la que fue sometida la misma población que, con sus sistemáticas destrucciones, se pretendía borrar todo resto de memoria. De allí que en la medida de esta situación, es nuestra intención visibilizar a un grupo de hombres dedicados no solo a una amplia gama de trabajos pastorales, sino también políticos y educativos. Con todo debieron ubicarse bajo su bandera y con ello enfrentarse a sus hermanos de religión que comandaban la fuerza armada española con los habitantes de las reducciones guaraníticas. Con estos últimos aparece otro grupo de protagonistas en una historia compartida que finalmente no favoreció a nadie.

Palabras Clave: Colonia del Sacramento, jesuitas portugueses, jesuitas españoles, provincia jesuítica del Paraguay.

\begin{abstract}
The permanence of the Portuguese Jesuits in Colonia del Sacramento lasted little more than half a century, enduring the hardships to which he was subjected to the same population, with its systematic destruction was intended to erase all traces of memory. Hence, the extent of this situation, we intend to make visible a group of men dedicated not only to a wide range of pastoral work, but also political and educational. Yet they should be placed under his banner and thereby confront his confreres who commanded the Spanish armed forces with the inhabitants of the Guarani reductions. With these last another group of characters appears in a shared history that ultimately did not favor anyone.
\end{abstract}

\footnotetext{
${ }^{*}$ CONICET-CIECS/UNC.
} 
Key words: Colonia del Sacramento, Portuguese Jesuits, Spanish Jesuit, Jesuit province of Paraguay.

Recibido: 10 de agosto de 2014

Evaluado: 20 de noviembre de 2014 


\section{Introducción.}

Cuando en 1854 la Junta Económica-Administrativa de Colonia del Sacramento confió al edil Luis Gil la misión de redactar un informe sobre su historia, se puede afirmar que se inició la historiografía de los colonienses ${ }^{1}$. No obstante encontrarse pasajes de su pasado escritos desde el siglo XVIII ${ }^{2}$, libros y artículos, como la publicación de fuentes documentales, por cierto son innumerables y condicen con la proporción de la riqueza de su tempestuoso devenir. Pero aún quedan infinidad de documentos por leer y temas por tratar que nunca se abordaron o se hicieron parcialmente. Uno de ellos es sobre la presencia de los jesuitas en Colonia, aunque el P. Serafim Leite SJ fue pionero y sus escasas páginas sobre el tema, publicadas desde 1938, no fueron superadas en la extensa bibliografía de Colonia ${ }^{3}$.

Al tratar sobre los ignacianos en Colonia del Sacramento debemos diferenciar claramente que se trata de los jesuitas de la Provincia del Brasil que no tenían relación con los de la Provincia del Paraguay, que igualmente recorrieron territorio uruguayo, desde mucho antes de la fundación de Colonia.

Los jesuitas llegaron a Brasil en 1549. Era un grupo de seis religiosos encabezados por el P. Manuel da Nóbrega que viajaron junto con el primer gobernador Tomé de Sousa (Fig. 1). Arribaron a Bahía y allí establecieron la primera casa del Instituto, cuya iglesia la consagraron a Nossa Senhora d'Ajuda. Continuaron constantes arribos hasta la expulsión (1559-1560). Se extendieron por todas las capitanías creándose formalmente la Provincia de Brasil en 1553, con el P. Nóbrega como provincial. Año en que se inició la aldea de Piratininga (actual São Paulo). Luego consiguieron fundación regia para las residencias de Bahía (1564), Río de Janeiro (1566) y Pernambuco (1574), que no estaban en principio destinadas a la enseñanza, pues a través de la prerrogativa real recibían una dotación de la corona para su subsistencia. Posteriormente se convirtieron en colegios de primeras letras, pero no fue la única actividad, sino que se sumó la evangelización de indios a través de las "aldeias" que serían una variante reduccional. El crecimiento y expansión impuso en 1727 la división de la viceprovincia de Maranhão.

La fundación de Colonia del Sacramento respondió a los mismos principios políticos con que Portugal fortificó sus fronteras, no solo en sus costas, sino hacia el norte, en la margen derecha del Amazonas, promoviendo la misión de Cabo Norte y hacia el sur con Colonia, en el Río de la Plata.

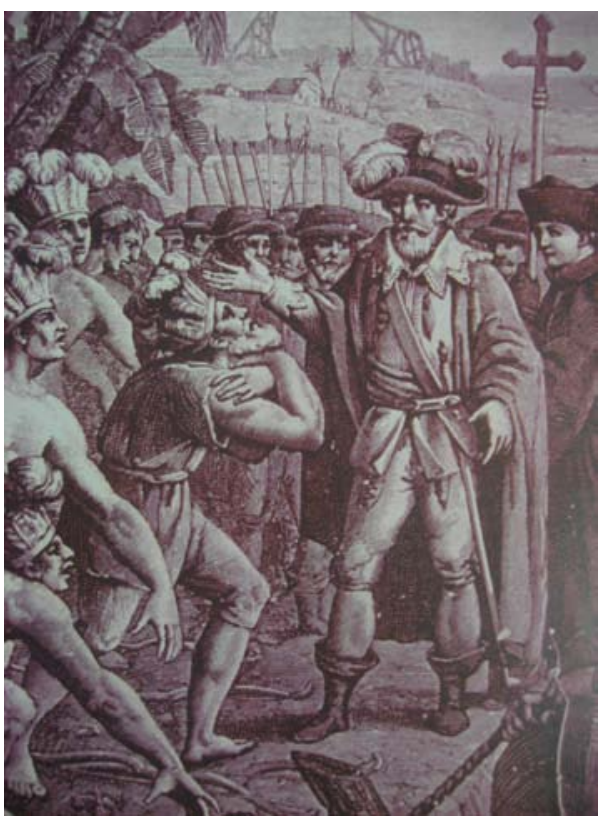

Fig. 1 Grabado del siglo XIX que representa el arribo a Bahía del gobernador Tomé de Sousa y donde se aprecia un jesuita, quizás el P. Nóbrega, por entonces de 31 años.

\footnotetext{
${ }^{1}$ Azarola Gil, 1931: 14.

${ }^{2}$ Ferreira da Silva, 1748. Pereira de Sá, 1900. Este último fue escrito entre 1737 y 1750 y recién impreso por el Lycêo Litterario Portuguez. Una reciente edición en Porto Alegre: Arcano 17, 1993.

${ }^{3}$ Leite, 2004.
} 
Aún antes del Tratado de Tordecillas de 1494, hubo siempre desavenencias territoriales entre las coronas españolas y portuguesas, que nacieron de las disputas por las Islas Canarias en el siglo XIV. En América, el Tratado tuvo varias interpretaciones, pues al establecerse 370 leguas al oeste del archipiélago de Cabo Verde, aún no se sabía con exactitud la dimensión esférica de la Tierra. Y nunca se midió. Si bien, a principios del siglo XVI Sebastián Gaboto intervino con su presencia en la costa oriental del Río de la Plata, también lo hizo, aunque frustradamente Martim Alfonso de Sousa.

Al instituirse la Provincia Eclesiástica de Brasil, el papa Inocencio XI por bula "Romani Pontifis" del 22 de noviembre de 1676 que creó la diócesis de San Sebastián de Río de Janeiro, reconoció que la misma abarcaría desde la Capitanía del Espíritu Santo hasta el Río de la Plata ${ }^{4}$. Esta disposición eclesiástica fue revalidada por otra civil y militar que se materializó en la expedición del flamante gobernador de Río de Janeiro.

De tal manera que los jesuitas estuvieron presentes en Colonia del Sacramento, tanto por la vía de Portugal (Brasil) como la de España (Paraguay), pero con objetivos distintos y hasta opuestos, defendiendo si se quiere ambas banderas sin que la religión sea un motivo de unión. Los del Paraguay, que ya habían incursionado por el actual Uruguay introduciendo ganado, tenían sus razones para que no se instalase la ciudad lusitana, pues sus reducciones habían sufrido el asedio de los paulistas a quienes veían como enemigos. Aunque los comuneros asunceños no les fueron a la zaga. Por todos los medios, los ignacianos trataron de evitar que se desarrollara esta especie de Gibraltar rioplatense durante décadas, lo que finalmente fue una derrota fatal: el Tratado de Límites de 1750.

Como corolario de ese acuerdo se desató la Guerra Guaranítica, siendo ésta, la única en que las coronas de España y Portugal dejaron de enfrentarse entre sí por Colonia del Sacramento, encontrando un enemigo común. Una guerra por la posesión de un enclave comercial estratégico que tuvo en vilo a la población por casi un siglo y medio, siendo los naturales de la región quienes sufrieron las consecuencias con sus propias vidas.

\section{La fundación de Colonia, los primeros jesuitas y la iglesia-residencia de San Pedro y San Pablo.}

Luego de ser designado gobernador de la capitanía de Río de Janeiro el general Manoel Lôbo, recibió precisas instrucciones de don Pedro II, príncipe regente de Portugal, fechadas el 18 de noviembre de 1678. En 36 capítulos ordenó ocupar territorios que se creían lusitanos en el Río de la Plata, con el objeto de conservar sus dominios. Además tuvo en cuenta reducir, exentos del servicio personal y para la fe cristiana, pueblos de indios compuestos de doscientas familias, a cargo de un religioso. Agrega el príncipe que les envió cartas al abad de San Benito y al rector de la Compañía de Jesús con el fin que aporten religiosos para la campaña ${ }^{5}$.

\footnotetext{
${ }^{4}$ Correa Luna, 1931: 55-64.

${ }^{5}$ Ibid.: 65-74. Da Costa Regio Monteiro, 1937, T. 2: 15.
} 
El rector de los jesuitas designó como capellán superior de la residencia y futuro colegio (primero de Uruguay) al P. Manoel Pedroso y por compañero al P. Manoel Álvares ${ }^{6}$. Poco antes de morir, el mismo Lôbo escribió de ellos:

“dos religiosos que traje conmigo de Río Janeiro, llamados el padre Manuel Pedroso y el padre Manuel Alvares, son personas de mucha doctrina, celo y ejemplo, y han sido en este naufragio fieles compañeros y consolación de todos, por más que quieran defender, por el buen nombre de la religión, las acciones de estos hombres, quedan convencidos por las experiencias y no llenen otra respuesta que encogerse de hombros"7.

El P. Pedroso (1639-1728) era paulista e ingresó en la Compañía de Jesús en 1657. Entre otros cargos, fue rector del colegio de São Pablo, cuando en 1695 concedió licencia al jesuita portugués António Rodrigues (1650-1736) para hacer un escrito sobre la última voluntad, por ser su confesor, del conquistador brasilero Jerónimo Bueno, fallecido en $1683^{8}$. El P. Pedrozo falleció en el colegio del Espíritu Santo a los 89 años de edad. Fue el primer superior de Colonia, donde profesó sus últimos votos, apenas llegado. Según el P. Leite era de "Bom genio para conciliar inimigos e apaziguar conflictos”9. Mientras que el P. Alvares (1629-1725) era de Portimão, población del sur de Portugal promovida desde entonces por el transporte marítimo de la costa africana. Ingresó al Instituto en 1645, permaneciendo muchos años en Colonia; como superior desde 1694, siéndolo luego de Porto Seguro y de Ilhéus (Bahía). Estuvo en las "aldeias" de indios y en su última morada, el colegio de Olinda, fue venerado como santo ${ }^{10}$.

Lôbo llegó a la isla de San Gabriel el 20 de enero de 1680 (Fig. 2). Buscó un lugar apropiado en tierra firme y para el 4 de febrero ya estaban construidos dos galpones de techos de paja para los soldados y para el día 10 habían concluido cuatro casas, una de las cuales era para los padres de la Compañía ${ }^{11}$.

Efectivamente, según testimonio del piloto José Gómez Jurado del 10 de febrero de 1680, hasta el momento en la isla había un "rancho pajisso", mientras que en tierra firme:

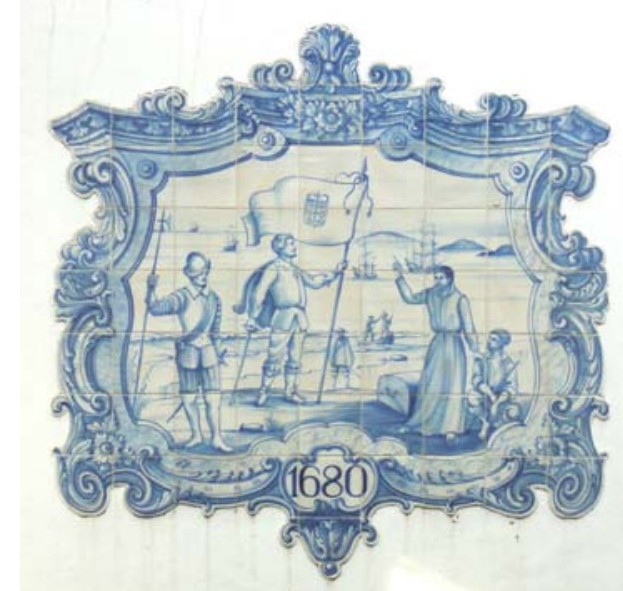

Fig. 2 Representación de la Fundación. El gobernador Lôbo, sus soldados y un religioso (Museo portugués de Colonia).

"vió una tienda de campaña blanca mas arriba alguna distancia vió dos Galpones ó ranchos grandes pajissos” (...) “donde se alojaban los indios y negros q, avian traido para el travajo dela Poblacion y q. avia alguna gente en ttierra en numero de quinientas personas" (...) "sobre mano isquierda de la

\footnotetext{
${ }^{6}$ Leite, 2004, T. II: 610.

${ }^{7}$ Carta do Govemador do Rio de Janeiro, D. Manuel Lóbo sobre os acontecimento sacorridos na Colónia do Sacramento, Buenos Aires, 3 de janeiro de 1683 (Azarola Gil, 1931: 191 y Leite, 2004, T.III: 611).

${ }^{8}$ Rodrigues, 1695.

${ }^{9}$ Leite, 2004, T. II: 559.

${ }^{10}$ Ibíd., T.III: 611.

${ }^{11}$ Regio Monteiro, 1937, T. 1: 47.
}

60 Carlos A. Page. La presencia de los jesuitas en Colonia del Sacramento ... 56-87. 
dha tienda para asi a la parte de este Rio cercano de lo referido otras dos cassas o ranchos" (...) "era Alojamiento de los soldados" (...). Agrega que "en dho puesto donde se formava la Ciudad tenia ya cinco casales con sus familias $y$ dos Padres de la Compañía de Jesus de aquel Reynos; dos de san fran ${ }^{c o}$. y otro de la misma religión de los descalssos $" 12$.

El trazado urbano de Colonia, e incluso muy posiblemente la elección del sitio, fue realizado por Antônio Correia Pinto, ingeniero de la capitanía de Pernambuco desde 1668. Pergenió una típica ciudad costera portuguesa, plaza-fuerte o villa fronteriza, ubicada en un sitio alto favorable a su carácter defensivo. Pero la construcción fortificada no llegó a concluirse, pues enterados los españoles, no tardaron en invadir y destruir el precario asentamiento.

Cuando la amenaza española se avizoraba, el gobernador Lôbo envió una comisión a Buenos Aires para solicitar provisiones. Estaba encabezada por el capitán Manuel Galvão y otros oficiales, además del P. Pedroso ${ }^{13}$. Llegaron el 24 de febrero, y el gobernador José de Garro no solo les negó el pedido, sino que les entregó una carta con amenazas para el gobernador portugués. Paralelamente Lôbo, pidió ayuda a Brasil y ordenó preparar las construcciones lo mejor posible para un previsible ataque.

Nuevamente y con toda la diplomacia que lo caracterizó, Lôbo envió en el mes de julio a Buenos Aires cartas al gobernador Garro, al Cabildo y al obispo, siendo portador de las mismas el P. Alvares ${ }^{14}$, pero las respuestas fueron tajantes en cuanto a la conminación del desalojo, que por otra parte estaba armando el maestre de campo Antonio de Vera Muxica, quien finalmente tomó la ciudad en la mañana del 7 de agosto.

Hubo muchas muertes en manos de los exaltados guaraníes; los sobrevivientes fueron puestos prisioneros, incluidos los dos jesuitas de Brasil. Escribe Manoel Lôbo que, sin embargo no mataron a sus negros e indios, pero arrasaron con "la iglesia de nuestros padres de la Compañía y la casa donde yo estaba” ${ }^{15}$. Lo corroboró Pereira de Sa cuando escribió que:

"O Pe Manoel Alvares comardente espirito, de que era dotado, sahio sem fructo a encontrar a multidão, que arrebatada como precipitados ribeiros, não navião vozes, que pudessem suspender o curso da cólera. Ao Ceo pedia castigo contra os Agressores da paz, pois excitando a guerra por huma ostentação vaidoza, vinhão-se a fazer os daños iguaes aos estragos. Tãopou copersuadião as palabras, que toda a eficacia era inútil, e toda ello quencia inftructuoza; por quanto empregados os olhos na vil, e insaciavel ambição, dezatendião a virtuoza elegancia de quem lhes mostraba verdade ${ }^{16}$.

Lôbo se encontraba enfermo y fue llevado prisionero a Buenos Aires donde murió en 1683. Lo acompañaron en su cautiverio dos capitanes, su capellán el P.

\footnotetext{
${ }^{12}$ Correa Luna, 1931: 122-123.

13 Riveros Tula, 1959: 66.

${ }^{14}$ Azarola Gil, 1931: 47. Riveros Tula, 1959: 71.

${ }^{15}$ Carta do Govemador do Rio de Janeiro, D. Manoel Lóbo sobre os acontecimentos acorridos na Colónia do Sacramento, Buenos Aires, 3 de janeiro de 1683 (Azarola Gil, 1931: 191 y Leite, 2004, T.III: 611).

${ }^{16}$ Pereira de Sa, 1993: 20.
}

61 Carlos A. Page. La presencia de los jesuitas en Colonia del Sacramento ... 56-87. 
Antonio Durāo de la Motta y el religioso jesuita Manoel Pedroso ${ }^{17}$. Ningún documento expresa que el $\mathrm{P}$. Alvares también haya sido prisionero, aunque igualmente con el tiempo regresó a Colonia. No obstante Riveros Tula afirma que de Buenos Aires fueron “dos jesuitas” restituidos a Colonia el 29 de abril de $1683^{18}$.

Tan solo poco más de seis meses, estuvieron los primeros jesuitas junto con los portugueses de la campaña del malogrado Manoel Lôbo. De lo que llegó a ser su Colonia por entonces, y más específicamente la residencia jesuítica, nos ilustran dos mapas de aquellos años que muestran el incipiente poblado en sus inicios fundacionales. El primero (Fig. 3), titulado "Plantta delineada... de la Ciudadela y su fortificación al tpo. q. fue avansada y demolida", pareciera estar incompleto y describe el acontecimiento de la toma y los sitios que se hallaban; entre los religiosos, mencionemos la "Iglesia de San Pedro y San Pablo" (I) indudablemente la residencia de la Compañía de Jesús, y la "Iglesia de San Francisco" (K). También sabemos por este plano que ya los portugueses contaban con "Fragua y horno de tejas".

Por otro lado y como en varios lugares, vemos que los jesuitas dieron la

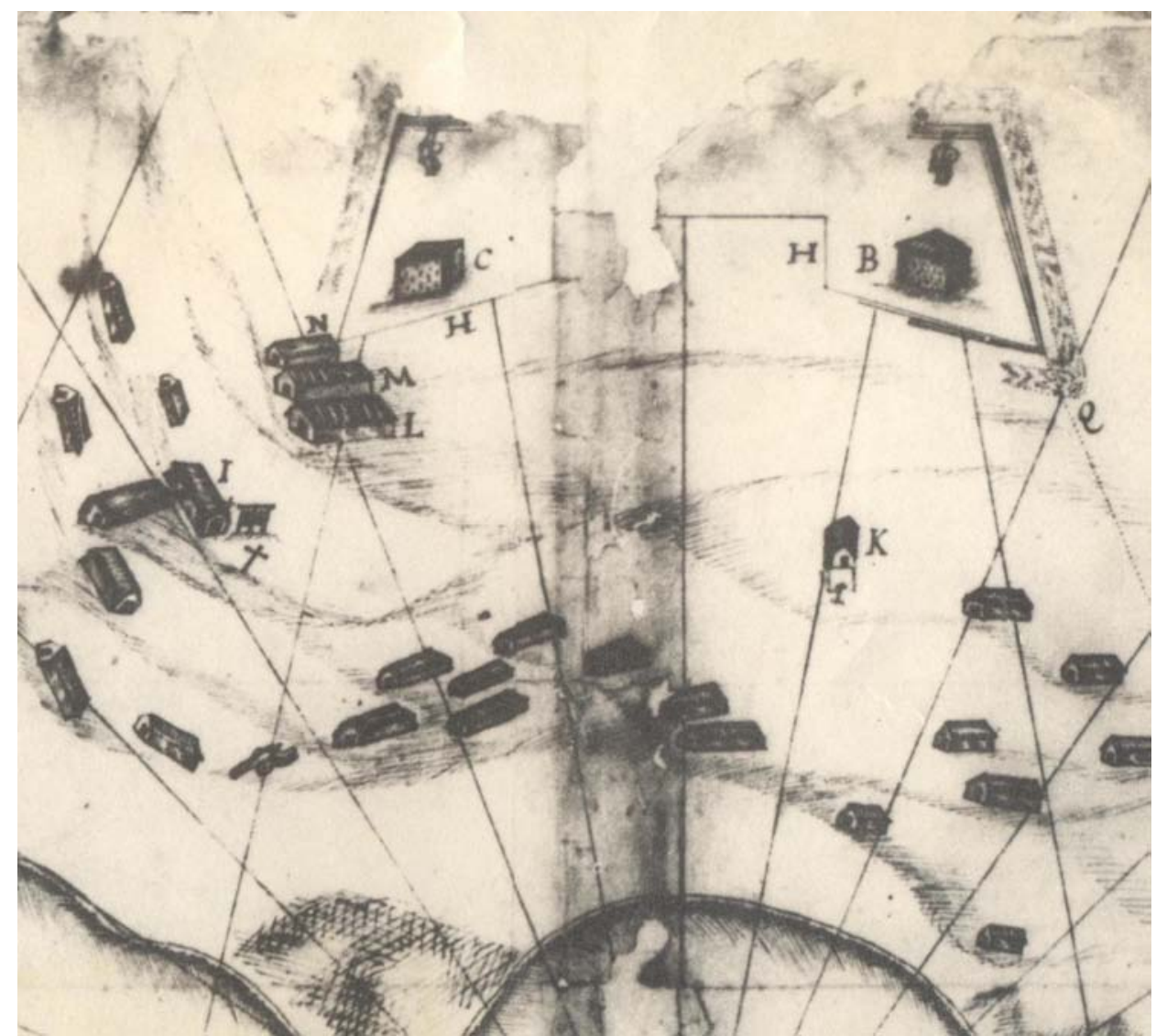

Fig. 3 Mapa de la toma de Colonia en 1680. Publicado en Correa Luna, 1931, T. 1 p.361 y Regio Monteiro, 1937, T. 2: 32

\footnotetext{
${ }^{17}$ Correa Luna, 1931, T.1: 233 y Jaime Cortesão, 1954a: 29.

${ }^{18}$ Riveros Tula, 1959: 95.
} 
advocación a su primera iglesia-residencia a San Pedro y San Pablo ${ }^{19}$. Su construcción, comparándola con las descripciones de los otros edificios existentes, no debe haber sido muy diferente; de muros de tapia o adobe y techos de paja que los españoles destruyeron con facilidad en agosto de 1680.

El otro plano (Fig. 4) fue trazado por Bernardo Antonio Meza en 1681, mostrando más detalladamente la toma de los españoles del año anterior. Muestra una planta perspectivada con una fortificación de base cuadrada con baluartes en los vértices (incompleta en su lado al Río de la Plata). En el interior solo se encontraban las casas de pólvora, de armas y la del cuerpo de guardia, hacia una gran plaza central. Por fuera del lado de la muralla y por el norte se ubicaba a la izquierda la casa y almacén del gobernador, un cementerio que indica el lugar de entierro de los que murieron en la toma (H), y la iglesia y casa de la Compañía (C y Q). A su derecha la de San Francisco (Y), mientras que el resto del espacio lo ocupaban casas, sin señalar Iglesia Matriz.

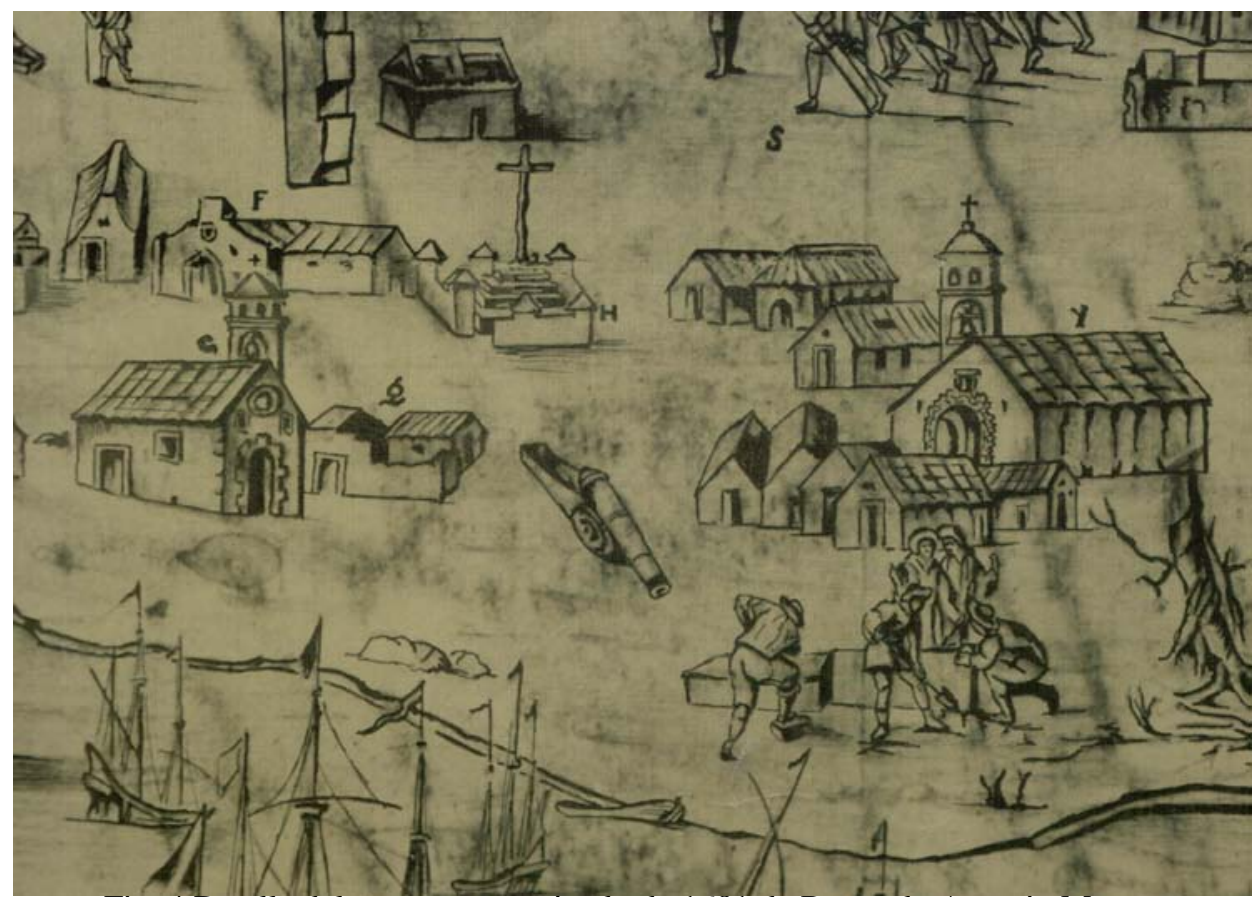

Fig. 4 Detalle del mapa perspectivado de 1681 de Bernardo Antonio Meza.

Este último mapa presenta con suficiente detalle la edificación de ambas iglesias, muy similares, de una nave, con techos a dos aguas, aparentemente de teja, $\mathrm{y}$ con espadañas o quizás torres adjuntas idénticas. Los ingresos llevan puertas de arco de medio punto. En la iglesia jesuítica hay dos pequeñas ventanas que podrían ser para un supuesto coro y el típico óculo, en una tipología arquitectónica de la que Il Gesù (15681577), poco atrajo la atención lusitana, quienes levantaban con anterioridad iglesias como la del Colegio del Espírito Santo en Évora (1557-1574) y la Casa Profesa de São Roque en Lisboa $(1566)^{20}$, considerada la primera iglesia jesuítica en suelo portugués. La fachada de esta última también es similar a la de São Paulo de Braga (Fig. 5), que se

\footnotetext{
${ }^{19}$ En América, los jesuitas levantaron colegios con estas advocaciones en los dos centros hispanos de mayor importancia como en México, fundado en 1572 y en Lima en 1568, con el colegio de San Pablo y su iglesia de San Pedro.

${ }^{20}$ Santos, 1963: 515-569.
} 
inició en 1567, aunque mucho más modesta en su planta. Pues este modelo influyó directamente en las primeras iglesias jesuíticas de Brasil, e incluimos en la larga lista, la de Colonia del Sacramento representada en el mapa señalado.

Una de ellas fue la del colegio de São Vicente, ya comenzado en 1559, es decir antes que las peninsulares, con una tipología que se tornó muy familiar con única nave con techumbre interior plana, más una fachada coronada por un frontón y una torre ubicada generalmente entre la iglesia y el colegio organizado a partir de un patio. Así también se distribuyó la residencia de Nova Almeida a fines del siglo XVI. Otro que se conservó fue el colegio de Olinda, comenzado en 1550 y reedificado en 1584 con una iglesia similar, aunque con transepto y capillas laterales poco profundas. La fachada sobria y elegante se asemeja a la sencillez de la de Braga (1567-1589) (Fig. 6). Igualmente a la del colegio de Rio de Janeiro construida en el Morro do Castello a partir de 1567 y demolida en 1922.

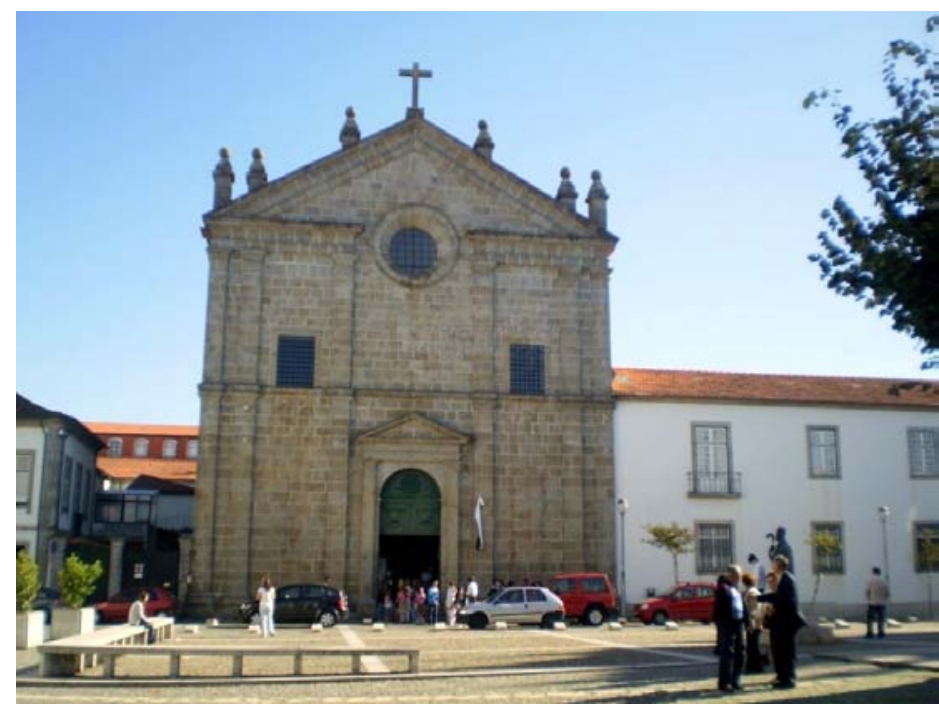

Fig. 5 Igreja de São Paulo de Braga.

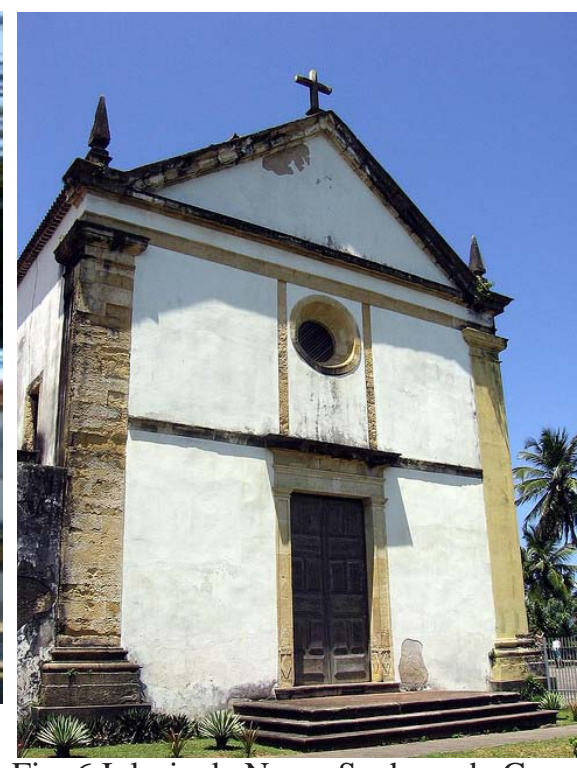

Fig. 6 Iglesia de Nossa Senhora da Graça y colegio de la Compañía de Olinda.

\section{La reconstrucción y una nueva destrucción.}

El 12 de febrero de 1683 el gobernador de Río de Janeiro, Duarte Teixeira Chaves recibió Colonia y el día 18 partió de allí a Buenos Aires el capitán Cristóvão de Almeida a hacer lo propio con los prisioneros que habían sobrevivido, pues algunos se fugaron, otros murieron y los esclavos fueron vendidos. Entre ellos estaban -como mencionamos arriba- los PP. Pedroso y Alvares que volvieron a Colonia, luego de dos años y medio de ausencia ${ }^{21}$. En un catálogo jesuita de 1683 se menciona la casa de los jesuitas, indistintamente como "Residência do Rio de la Prata" o "Residência da Nova Colónia dos Portugueses" 22 .

Comienza la reconstrucción de Colonia, de lo poco que había quedado del saqueo y tanto tiempo de abandono. El gobernador regresó a Río de Janeiro y dejó Colonia a cargo del maestre de campo Chistovão de Ornellas de Abreu quien

\footnotetext{
${ }^{21}$ Regio Monteiro, 1937, T. I: 101.

${ }^{22}$ Leite, 2004, T. II: 611.
} 
permaneció cinco años, siendo reemplazado en 1689 por don Francisco Naper de Lencastre. Siguió una década de gobierno fructífero donde el viejo rancherío fue sustituido por una ciudad progresista, con plaza, iglesia y viviendas de piedra y ladrillo, cubiertas con tejas. Aunque tuvo ciertas desavenencias con los jesuitas que obligó a que uno de ellos se retirara de Colonia ${ }^{23}$.

Después de 1683 quedó como superior de la residencia de los jesuitas, el portugués profeso de cuatro votos Domingos Dias (Familacão, 1638 - Rio de Janeiro, 1715), llegado al Brasil en 1655. Luego fue rector de los colegios de Santos, San Pablo y Recife. Escribe el P. Leite que por su incansable labor con los esclavos mereció inscribirse en el Menologio del Brasil. Fue sucedido por el sacerdote carioca Nicolau de Sequeira (Río de Janeiro, 1657-1721), que ingresó al Instituto en Brasil en 1673, alcanzando sus últimos votos en 1690 en su ciudad natal ${ }^{24}$, cuando luego se trasladó a Colonia.

El P. Sequeira ejercía de párroco e inició los libros de la iglesia en mayo de 1690 -como señala Carlos G. Rheingantz- con el casamiento del teniente Leonel da Gama Bellenas con María Josefa Correa, quienes tuvieron cinco hijos en los 15 años que vivió en Colonia ${ }^{25}$. También los jesuitas bautizaron indios, como lo hizo el P. rector Luiz de Amorim (1654-1730), quien incluso fue autorizado por el provincial de Brasil y el Consejo Ultramarino portugués para crear una reducción entre los minuanes ${ }^{26}$ en el sitio llamado "Riachuelo". Aunque tal población no llegó a concretarse por las dificultades de la guerra de $1704^{27}$, cuando ya había partido el P. Amorim, luego de ocho años en Colonia y pasar como profesor de Moral al colegio de Río de Janeiro, posteriormente visitador y superior de las misiones de Maranão, rector del colegio de Olinda y del Espírito Santo de su tierra natal, donde falleció ${ }^{28}$.

Dos palabras más sobre los minuanes. Según el P. Leite, para 1727, los 23.000 minuanes de Rio Grande solicitaron que fueran a evangelizarlos y reducidos por los jesuitas de Paranaguá. Pero era una misión que no se podía concretar sin la licencia real, sin embargo se encomendó la tarea a los jesuitas de Laguna y Colonia de Sacramento ${ }^{29}$. Recién en 1750 se celebraron los bautismos de unos 60 minuanes, siendo padrinos el gobernador y otras personas importantes. Para este tiempo tanto los tapes como los charrúas habían atacado frecuentemente a los minunaes. Sobre ellos escribe el P. Leite:

\footnotetext{
${ }^{23}$ Azarola Gil, 1931: 80-84. Posiblemente fue el P. Alvares, de quien sabemos estuvo por última vez en Colonia en 1694 (Storni, 1980: 10).

${ }^{24}$ Storni, 1980: 82 y 271. Leite, 2004, T. III: 274.

${ }^{25}$ Riveros Tula, 1959: 106.

${ }^{26}$ Fueron una parcialidad de los charrúas que se ubicaban en el interior de la provincia de Entre Ríos en la República Argentina y al norte del río Negro en la República Oriental del Uruguay hasta el río Ibicuy en el estado de Río Grande del Sur en el Brasil. En la provincia del Paraguay, el jesuita Francisco García (1686-1731) llegó a formar una reducción con esta parcialidad que llamaron de Jesús María, ubicada junto al río Ibicuy, pero no tuvo éxito. Los pocos que se redujeron se unieron luego a la reducción de San Borja (Azara, 1847: 145-146). También los jesuitas del Paraguay intentaron fundar para 1722 otra reducción con los guenoas, como así llamaban ellos a los minuanes, habiendo designado para la ocasión a los PP. Diego Claret y Juan de Yegros y con el objeto que cuiden las vaquerías del mar (AGN, S. IX, 6-95, Doc. 369, Memorial del P. Provincial Joseph de Aguirre Para el P. Superior del Paraná y Uruguay y sus consultores en la visita de 1722).

${ }^{27}$ Riveros Tula, 1959: 123. Storni, 1980: 12.

${ }^{28}$ Leite, 2004, T. III: 202.

${ }^{29}$ Ibíd., T. II: 605.
} 
"Era de génio e naturaleza bastante doce e amicíssimos dos Portugueses, de que é suficiente provanão haver noticia que Minuano roubasse ou matasse portugués algum”. Los contactos para formar la aldeia los venía haciendo el P. Nogueira con el cacique Xiclano. Leite también describe a los minuanes "O vestido que usam os indios Minuanos consiste em algumas peles de cervo. Ásíndias, logo que nascem, lhes fazem na testa uma cruz de côr azul que chega até o nariz; é costume ainda destas mulheres, quando more algum dos seus parentes próximos, cortar o nó dos dedos das mäos. Comuma se encontroum dos dois missionários, a qual já näo tinhan as mäos, senão um ou dois dedos ilesos. Também os homes fazem as suas demostrações, que é ferirem os própios braços e espáduas com frechas, enxergando-se, depois, tanto nos braços como as espáduas, os sinais das feridas. O que é muito común ver-se naqueles bárbaros”30.

Una relación sobre Colonia del Sacramento escrita en 1704 por el gobernador de Buenos Aires don Alonso Juan de Valdés Inclán, además de tratar cómo era la fortaleza, con sus cuatro baluartes, señala que el pueblo formado extramuros era "con casas de tierra, y paja: un Hospicio de Religiosos de San Francisco, y otro dentro de la Plaza de la Compañía de Jesus”. Agregando que tenían sus huertas ${ }^{31}$.

Colonia prosperaba en todos los aspectos. Por ejemplo el gobernador Sebastião da Veiga Cabral, que había asumido en 1699, había traído de Río de Janeiro piedras, cal y canteros para la iglesia. Pero también el poblado comenzó a convertirse en refugio de exiliados, lo cual dificultó la vida social y religiosa. La paz entre ambas coronas continuaba, aunque los españoles fomentaban y encubrían las tropelías de los indios contra la ciudad portuguesa. Por ese motivo el gobernador envió en el año 1700 a Buenos Aires, al mencionado jesuita P. Amorim para que vaya a reclamar por tales hechos $^{32}$, culpando indirectamente, no a los españoles sino a los jesuitas de las reducciones. Este conflicto quedó minimizado con el Tratado de Mútua Aliança entre España y Portugal, firmado en Lisboa el 18 de junio de 1701, donde Portugal apoyaba a Felipe $\mathrm{V}$ en una inminente guerra de sucesión. Pero al año siguiente volvieron a atacar los indios y la propia casa de los jesuitas de Colonia fue quemada y el ganado que contaban para su sustento se dispersó ${ }^{33}$. Sobrevino la guerra que declaró Felipe V a Portugal en 1704, y los españoles sitiaron Colonia, en tanto el gobernador de Buenos Aires Valdés e Inclán, nuevamente usó a los jesuitas como mediadores, pero no resultó y luego de un sitio de cinco meses, el 15 de marzo de 1705 los portugueses abandonaron Colonia. Al día siguiente hizo su entrada a la ciudad el triunfante gobernador y ordenó la demolición, tarea que estuvo a cargo de los guaraníes, quienes a su vez cometieron varios hechos vandálicos, como el asalto a la iglesia ${ }^{34}$.

En un viaje que hizo el jesuita del Paraguay H. Silvestre González (Huelva, 1657-Candelaria, 1708) con el P. Juan María De Pompeo (Benevento, 1661 - San Javier, 1716) por las vaquerías que se encontraban en la banda oriental, escribe su impresión de Colonia de esta manera:

"El lunes veinte y tres (noviembre de 1705) llegué a San Gabriel, y desde una loma estuvimos mirando y remirando, y vimos no había nadie y que tampoco

\footnotetext{
${ }^{30}$ Ibíd.: 607.

${ }^{31}$ Correa Luna, T. 1: 433 y Capurro, 1928: 21.

${ }^{32}$ Correa Luna, 1931, T.1: 400-408.

${ }^{33}$ Leite, 2004, T. II: 612.

${ }^{34}$ Pastells, 1933, T. V: 538.
} 
había navío alguno ni embarcación alguna en el puerto. Con todo, cogí tres indios y me fui allá, y hallé no había rastro de persona viviente, ni en tierra ni en el Río. Anduve viendo aquello, y para el concepto que yo tenía hecho, me pareció una suma pobreza. Todo está demolido, menos las paredes de la iglesia, que son de cal y canto; en lo demás no hay nada en forma, ni aun que se pueda hacer juicio de lo que era, si no es quien lo vido antes" 35 .

Las ruinas del poblado portugués quedaron abandonadas por una década. Pero con los tratados concluidos en Utrecht en 1715, que puso fin a la Guerra de Sucesión Española, Colonia del Sacramento fue restituida a Portugal a fines del año siguiente. Pero todo estaba nuevamente destruido y el flamante gobernador Manoel Gomes Barbosa debió hacerse cargo de la reconstrucción y repoblación con familias portuguesas. Y allí vendrían con el gobernador, dos jesuitas, por mandato de João V, a fin de administrar los sacramentos a los soldados. Pero ante todo era una decisión política, pues el rey sabía que los jesuitas tenían facilidad para tratar con los indígenas, y supuestas buenas relaciones con sus pares del Paraguay que dominaban a los indios y las tierras. Recibían de la corona para la manutención de dos individuos, la suma de setenta mil reales y raciones de harina de mandioca, aceite, sal, legumbres y arroz, aunque también los vecinos los ayudaban con limosnas ${ }^{36}$. En 1717 comenzaron a reconstruir la residencia que ahora pasaba a la categoría de colegio y con una nueva advocación, esta vez la de San Francisco Javier.

\section{Los jesuitas españoles frente a los portugueses.}

Es necesario hacer un paréntesis sobre las relaciones entre los jesuitas portugueses y españoles, sin dejar de soslayar la participación de los pueblos jesuíticoguaraní. Pues ciertamente el territorio que ocupaban éstas últimas era mucho más amplio del urbano, extendiéndose a las “estancias” de la banda oriental del río Uruguay, cuyos límites naturales aproximados se ubicaban desde el Río Negro al sur hasta el Ibicuy al norte, y hacia el este hasta alcanzar el océano. Esta extensa región fue poblada de ganado por los jesuitas quienes debieron abandonarlo ante el avance paulista de 1636. Se refundaron a principio del siglo XVIII como estancias comunales, primero de Yapeyú, luego de San Miguel y más tarde se crearon las Vaquerías del Mar y la de los Pinares (Fig. 7). Cada estancia poseía una capilla y era administrada por un jesuita ayudado por varios indios. Eran regiones muy extensas que respondían al particular concepto de "estancia" dado por los guaraníes, en amplia correlación con la "caza”, de allí el término "vaquería”37.

De tal manera, la región era ampliamente dominada por los guaraníes cristianos, y Colonia del Sacramento se convirtió en un foco de tensión permanente en la región rioplatense, ante la indefinición de límites de su tiempo que produjo una continua agresividad por parte de la corona española que se valió de los guaraníes reducidos, como verdadero ejército contra Portugal, legalizado definitivamente por la Real Cédula del 25 de julio de 1679 que resolvía armar a los indios pero bajo responsabilidad de los jesuitas. Efectivamente las reducciones de guaraníes contaron con jesuitas con el cargo

\footnotetext{
${ }^{35}$ González, 1966.

${ }^{36}$ Possami, 2006: 304-305.

${ }^{37}$ Levinton, 2009: 243-266.
} 
de "superintendente de guerra" con sus "consultores". De dos que había en 1714 pasaron a ocho en 1748. Cada reducción tenía una armería, presidida por un retrato del rey, donde guardaban armas de fuego y la pólvora que ellos mismos producían. Incluso

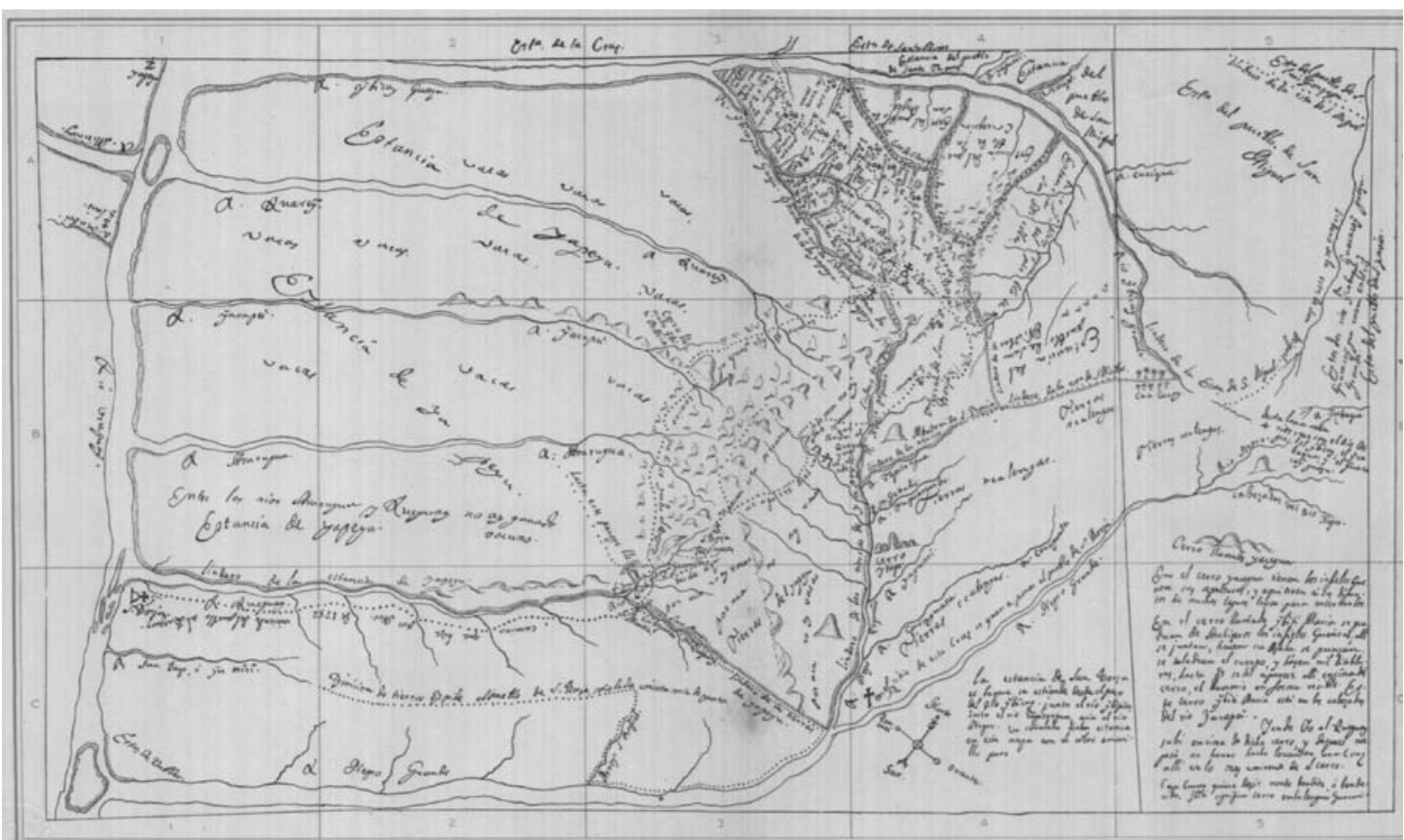

Fig. 7 Mapa de las estancias que tenían los pueblos misioneros al oriente del Río Uruguay. Fue realizado posiblemente por el P. Nusdorffer o el P. Marimón en 1752 (Furlong, 1936. Número LXXI. Mapa XXIV: 80).

se promovían los "ejercicios de armas" o "simulacros de guerra”, como el tiro al blanco, además de contar cada pueblo con 200 caballos de reserva para la guerra ${ }^{38}$.

Sobre la fundación de Colonia, el gobernador Garro no solo fue advertido por su par de Paraguay, Felipe Rex Corvalán, sino también por el superior de las reducciones el P. Cristóbal Altamirano (Santa Fe, 1602-Apóstoles, 1698), a través del teniente de gobernador de Corrientes y también por informe propio al mandatario de Buenos Aires que de inmediato ordenó al jesuita que aliste 3.000 indios de las reducciones ${ }^{39}$ y dos sacerdotes "porque no pierdan de vista sus Padres espirituales", para lo cual envió a un oficial a preparar las tropas guaraníes, que serían acompañados por 250 españoles al mando del maestre de campo Antonio de Vera Mujica ${ }^{40}$.

Mientras se preparaban las tropas guaraníes, los jesuitas Jerónimo Delfín (Valladolid, 1635-San Ignacio, 1714) y Domingo Rodiles (Oviedo, 1630-San Carlos, 1703) y sus 300 tapes, pusieron prisioneros a un grupo de portugueses al mando del teniente general Jorge Soares de Macedo ${ }^{41}$, que naufragó por las costas de Montevideo

\footnotetext{
${ }^{38}$ Furlong, 1978: 388-389.

${ }^{39}$ Pastells, 1918, T. III: 287.

${ }^{40}$ Ibíd.: 277 “Carta del gobernador Garro al P. Altamirano, 7-2-1680”.

${ }^{41}$ Soares Macedo (Obidos, 1634 - Santa Fe, 1693) quedó en libertad y se trasladó a Santa Fe. Allí estuvo en contacto con los jesuitas, especialmente con el P. Miguel Ángel Serra. Con este sacerdote sardo que fue rector del colegio, Soares hizo los Ejercicios Espirituales e ingresó a la Compañía de Jesús como hermano coadjutor en 1683 (Storni, 1980: 169).
} 
con rumbo a Colonia para hacerse cargo de la gobernación. Los diez portugueses, ocho indios tupíes, cinco esclavos africanos y un religioso franciscano fueron llevados a Yapeyú y de allí el P. Pedro Jiménez (Logroño, 1637-Santiago del Estero, 1705) los trasladó a Buenos Aires el 27 de abril de $1680^{42}$.

Los jesuitas acompañaron la toma de Colonia y fue el P. Pedro de Orduña ${ }^{43}$ (Zaragoza, 1629-San Javier, 1700), procurador general de las misiones, quien llevó a los guaraníes de las reducciones ${ }^{44}$, junto a los PP. Juan de Rojas (Asunción, 1619-La Rioja, 1697), Jacinto Márquez (Teruel, 1645-Yapeyú, 1683), y el futuro mártir Juan Antonio Solinas (Oliena, 1643-Chaco, 1683) ${ }^{45}$. Los guaraníes bajaron por el río Uruguay hasta el río Negro donde se hallaba el real en la reducción de Santo Domingo Soriano $^{46}$. Estuvieron por tres meses y algunos de ellos llegaron a comercializar carnes y cueros con los portugueses. Eran alrededor de 3.000 almas divididas en tres escuadrones al mando del cacique Ignacio Amandau de la reducción de San José, Francisco Cureta de Itapua y Cristóbal Capis de Santo Tomé, además de habitantes de Apóstoles, un capitán por cada tercio y 50 soldados del presidio.

La efectiva contienda duró apenas una hora, de la madrugada del 7 de agosto, quedando un centenar y medio de muertos, muchos heridos y el resto prisioneros. Entre ellos 45 africanos que fueron vendidos y 150 tupíes que se repartieron entre los vecinos de Buenos Aires ${ }^{47}$. En Colonia, los españoles dejaron "una atalaya, guarnecida por un Cabo, 25 hombres y cuatro piezas de artillería” ${ }^{48}$. Antes de su muerte, Lôbo escribió una carta al príncipe regente, fechada el 3 de enero de 1683 acusando a Garro por el mal trato a prisioneros de guerra y a los jesuitas españoles de las reducciones guaraníticas que habían ordenado la matanza de los portugueses con tanta crueldad.

Pero el 7 de mayo de 1681 se firmó en Lisboa un convenio de 17 puntos para la restitución de Colonia del Sacramento al gobernador portugués y el día 28, Carlos II rubricó la Real Cédula de cumplimiento del mismo. Mientras tanto, España envió al jesuita cosmógrafo real y catedrático Juan de Andosilla (Murcia, 1644-Roma, 1685) para que junto al capitán Francisco Gómez Jurado reconocieran la costa, como quedó establecido en el convenio ${ }^{49}$.

\footnotetext{
${ }^{42}$ Cortesão, 1954a: 56-58. Pastells, 1918, T. III: 293, Correa Luna, 1931, T.1: 181-182.

${ }^{43}$ Una completa información de los acontecimientos la escribió el P. Orduña al provincial: "Relación y carta del P. Pedro de Orduña del avance de indios al fuerte portugués y victoria que ganaron a 7 de agosto de 1680” (ANCh, Jesuitas Argentina, vol. 197, n. 1, ff. 2-5).

${ }^{44}$ Correa Luna, 1931, T. 1: LV.

${ }^{45}$ Cortesão, 1954a: 380.

${ }^{46}$ Azarola Gil, 1931: 45. La reducción de Santo Domingo Soriano era un enclave ubicado en actual territorio uruguayo, en la confluencia de los ríos Negro y Uruguay. Fue fundada por los franciscanos en 1624, con indios chanáes, aunque luego se suman guaraníes y charrúas. El sitio original fue la isla Vizcaíno o Isla de los Caballos, trasladándose luego a la isla Yaguarí-miní en 1664, donde se levantó un fuerte ante los persistentes ataques lusitanos, para volver a su lugar iniciar en 1664 y trasladarse a su actual emplazamiento urbano en la margen sur del Río Negro en 1718 (Marotta Castro, 2000). Va a ser en lo sucesivo el sitio de encuentro de los guaraníes que bajaban de las reducciones para los ataques a Colonia del Sacramento.

${ }^{47}$ Correa Luna, 1931, T. 1: 236.

${ }^{48}$ Pastells, 1918, T. III: 334.

${ }^{49}$ Pastells, 1918, T. III: 382. “Decreto de SM del 23 de junio de 1681”.
} 
Un documento borrador (aunque existen varias copias) de letra de Bernardo Nusdorffer de 1735 , cuando era superior de las misiones ${ }^{50}$ se refiere a los servicios prestados por los indios de las reducciones a la corona española desde 1637. Señala en el punto 16 sobre el año 1680 que por orden del gobernador de Buenos Aires José de Garro bajaron tres mil indios armados para desalojar por primera vez a los portugueses de Colonia del Sacramento. Llevaban 4.000 caballos, 200 bueyes y 37 balsas, entre otros pertrechos y alimentos. Fueron caminando en invierno a lo largo de 150 leguas para no maltratar a los caballos: "obraron en el asalto de aquella fortaleza con no menos valor, y constancia, q los soldados españoles, señalándose en la lealtad y zelo del Rl. servicio”. No obstante murieron 33 indios y quedaron 104 heridos en un sitio que duró seis meses.

Las rondas de los indios reducidos por las costas uruguayas seguían siendo frecuentes, como lo eran operaciones militares menores y las continuas convocatorias a la defensa del puerto y ciudad de Buenos Aires, de Corrientes (1721), Asunción (17241733) o Santa Fe (1725), además de ser llamados para la construcción de edificios como el fuerte porteño. Siempre a su costa, a pesar de la Real Cédula del 29 de noviembre de 1679 que establecía el pago de un real y medio por día a cada soldado, pero casi nunca cobraron nada.

Para el segundo desalojo de Colonia y por mandato del gobernador Valdés Inclán y a las órdenes del sargento mayor Baltasar García Ros, llegaron a las afueras de Colonia en noviembre de $1704^{51}$, la suma de 4.000 indios armados, que llevaron 6.000 caballos, casi 2.000 mulas y varias embarcaciones, además de provisiones a su costa que incluían 30.000 vacas para sustentase ellos y los españoles. El sitio duró ocho meses y esta vez murieron 130 indios, quedando 200 gravemente heridos. En un informe del gobernador de Tucumán don Esteban de Urizar y Arespacochaga, expresa que el 8 de setiembre marcharon tres cuerpos de soldados teniendo como capellán de los españoles al jesuita italiano P. Pablo Restivo (Caltanisetta, 1658-Candelaria. 1740). Mientras capellán de los guaraníes y superior fue el P. José Mazo ${ }^{52}$ (Alcora, 1658-Río Paraná, 1717). Estuvieron a cargo los caciques de San Borja, San Miguel, Candelaria y Yapeyú: Diego Gaybipoi, Bonifacio Capi, Juan Mañari y Pedro Mbacapi, aunque también

\footnotetext{
${ }^{50}$ AGN, S. IX, 6-9-7, Doc. 60 "Relacion compendiosa delos servicios q han hecho â su Mag ${ }^{d}$. los Indios delas Doctrinas, q estan â cargo delos PP. dela Comp ${ }^{a}$. de Jesus en esta Provincia del Paraguay de Nacion Guaranis, ô como los llaman vulgarmente tapes, desde el año 1637 hasta Otubre del presente 1735, así en el distrito del Govierno de Buenos Ayres, como en el del Paraguay” 1735. Publicado en parte por Hernández, 1913, T. II: 63-73.Teschauer, 1922, T. III: 157-173, entre otros.

${ }^{51}$ El virrey del Perú conde de Monclova le comunicó a Valdés Inclán, el 12 de junio de 1704, la resolución del rey de recuperar por las armas Colonia del Sacramento (Pastells, 1933, T. V: 29). Pero era de parecer que "se demuela y arrase dicha Colonia, por ser dos las plazas que se habrían de mantener, y una vez demolida juzga no han de ir de nuevo á levantarla los portugueses” (Ibíd.: 43).

${ }^{52}$ Destacamos al P. Mazo pues murió mártir. Llegó a Buenos Aires en la expedición de los PP. Grijalva y Donvidas en 1681. Estudió en Córdoba y después de su ordenación fue enviado a las reducciones guaraníticas (1688-1692). Luego fue procurador de ellas en Buenos Aires, donde también ocupó el cargo de rector (1705-1707), como también en el colegio de Santa Fe (1708-1710). Después regresó a las reducciones, quedando a cargo de San Ignacio Miní. El 10 de setiembre de 1717 fue asesinado por los payaguás, junto al P. Blas de Silva y 30 guaraníes, cerca de Itatí a orillas del Paraná (Furlong,1944, T. 1: 302). También el P. Mazo escribió una relación de aquellos acontecimientos: "Relación de lo que hicieron los indios que tienen a su cargo los religiosos de la Compañía de Jesús de la Provincia del Paraguay en servicio del rey (Dios guarde) en la conquista de la colonia portuguesa, sita en tierra firme, enfrente las islas de San Gabriel”, Buenos Aires, 12 de setiembre de 1705 (ANCh, Jesuitas Argentina, vol 197, n. 7, ff. 43-48v).
} 
asistieron guaraníes de San Nicolás y San Cosme. Irían en calidad de capellanes jesuitas, el francés José de Tejedas (Perpiñán, 1664-Candelaria, 1744), los españoles Juan de Anaya (Sevilla, 1667-San Borja, 1742), y quien llegó a provincial el P. Jerónimo Herrán (Santander, 1672-Córdoba, 1743) y Pedro (o Francisco) de Medina (Santiago del Estero, 1637-San Carlos, 1717). Además de los coadjutores "cirujanos" Pedro de Montenegro (Galicia, 1663-Mártires, 1728), Joaquín de Zubeldía (Tolosa, 1657-San Borja, 1732) y José Brasaneli ${ }^{53}$ (Milán, 1658-SantaAna, 1728). El verdadero médico era el H. Montenegro, que había estudiado medicina en el Hospital General de Madrid, mientras que los otros dos posiblemente eran ayudantes, de hecho Brasaneli era un eximio artista. Agrega el P. Furlong que en aquella oportunidad el H. Montenegro “ayudó a 200 heridos y a muchos enfermos de epidemias”, especialmente disentería ${ }^{54}$. Pues los guaraníes no solo construyeron hospitales sino también iglesias, la casa del gobernador, además de viviendas para los soldados españoles y para ellos mismos.

No menciona el P. Nusdorffer, la ferocidad con que los indios arrasaron Colonia, pues según informó el gobernador de Buenos Aires al virrey, tanto españoles como jesuitas intentaron que no entraran los guaraníes a la ciudad, mientras los portugueses huían en cuatro navíos. Pero no pudieron contenerlos con persuasión, saqueando y quemando casas, además de entrar a la iglesia rompiendo cuanto encontraban y cargando con lo poco que habían dejado los portugueses que se llevaron cuanto pudieron. Los soldados se fueron y el P. Mazo quedó solo junto a sus compañeros de religión ${ }^{55}$. Finalmente el virrey informó al rey que según le trasmitió el gobernador Valdés Inclán en carta del 28 de mayo de 1705 "concluyó la demolición de la fortaleza, dejándola toda arrasada y llevándose a Buenos Aires todos los pertrechos que se hallaron en ella ${ }^{, 56}$.

En 1718 el flamante gobernador Bruno Mauricio de Zabala envió 500 indios para vaquear por tres meses en los alrededores de Colonia del Sacramento donde se defendieron los portugueses, matando algunos indios y entre ellos fue herido y preso un coadjutor de la Compañía de Jesús. Jaime Cortesão hizo detallada referencia a estos hechos, expresando que los jesuitas que comandaban aquella expedición eran el P. Juan de Yegros (Asunción, 1671-Corpus, 1725) y el H. Marcos Villodas (Alava, 1695-Santa Fe, 1741), quien fue llevado preso a Colonia ${ }^{57}$.

Siguiendo con el documento del P. Nusdorffer, el mismo mandatario, en 1724, hizo alistar 4.000 indios para expulsar a los lusitanos de Montevideo que pretendían poblar, pero al enterarse de estos aprestos, los portugueses se fueron y la mitad de los guaraníes regresaron a sus reducciones, el resto se puso a construir el fuerte de Montevideo, siempre y como de costumbre, sustentándose con sus propios animales y bastimentos. Diez años después y antes de haber concluido el grave conflicto del Tebicuary en Paraguay, el gobernador de Buenos Aires Miguel de Salcedo solicitó 3.000 indios armados, que llegaron con los capellanes de campaña, el jesuita belga Lorenzo Daffé (1677-San Luis, 1748), el francés José Guinet (Ille, 1683-San José,

\footnotetext{
${ }^{53}$ Ibíd.: 61-63.Charlevoix, 1913, T. IV: 377. Azarola Gil, 1931: 89.

${ }^{54}$ Furlong, 1942: 67.

${ }^{55}$ Pastells, 1933, T. V: 57. “Carta del gobernador al virrey 20 de marzo de 1705”.

${ }^{56}$ Ibíd.: 95. “Carta del virrey al rey 10 de agosto de 1705”.

${ }^{57}$ Cortesão, 1954b: 147.
}

71 Carlos A. Page. La presencia de los jesuitas en Colonia del Sacramento ... 56-87. 
1758) y Diego Matías Araoz (Tucumán, 1709-La Cruz, 1750) ${ }^{58}$. Aunque el mismo gobernador, terminado el sitio a Colonia en febrero de 1738, ordenó con aspereza al P. Daffé que se retirara con sus indios a las reducciones porque estos comercializaban carne con los portugueses sitiados ${ }^{59}$.

El gobernador de Buenos Aires Miguel de Salcedo, intimó a su par de Colonia Antônio Pedro de Vasconcelos a fines de 1735, por el incumplimiento de la pactada demarcación de los límites del ejido de Colonia, que comprendía un tiro de cañón desde su plaza. Por tanto mandó a desalojar a todos los estancieros que se ubicaban fuera de ese límite. Anticipadamente Salcedo convocó otra vez a los jesuitas para que aportaran 4.000 indios de las reducciones ${ }^{60}$. El 28 de noviembre comenzaron a tronar las baterías del sitio. Fue cuando murió el jesuita Tomás Werle (Munich, 1688-Colonia, 1735) ${ }^{61}$ y desertaron 300 indios. También en esta ocasión los indios llevaron carne a Colonia a cambio de telas, actitud que reconocieron los mismos jesuitas que reprendieron a quienes lo hicieron, mientras que los españoles fusilaron a nueve y culparon a los guaraníes por su fracaso, enviando a gran parte de ellos y sin provisiones a sus reducciones ${ }^{62}$.

En los acontecimientos de 1736 una vez que comenzaron los bombarderos, que causaron daños en la iglesia matriz, el brigadier Vasconcelos ordenó llevar el Santísimo a la iglesia de los jesuitas ${ }^{63}$.

Luego de un periodo de tranquilidad aparente, se sucedió la Guerra Guaranítica, donde por el Tratado de Límites de 1750, Colonia debía ser canjeada por siete pueblos jesuítico-guaraní. Los ignacianos hicieron lo imposible por evitar esto, enviando una representación formal fechada el 12 de marzo de $1751^{64}$. Hasta elaboraron un mapa ${ }^{65}$ (Fig. 8) realizado por el P. José Cardiel en 1752 que entregó personalmente el $\mathrm{P}$. Lope Luis Altamirano al marqués de Valdelirios, para evitar la guerra. Se marca a la derecha en línea roja, la mediación del papa Alejandro VI (1494); lo sombreado corresponde al Tratado

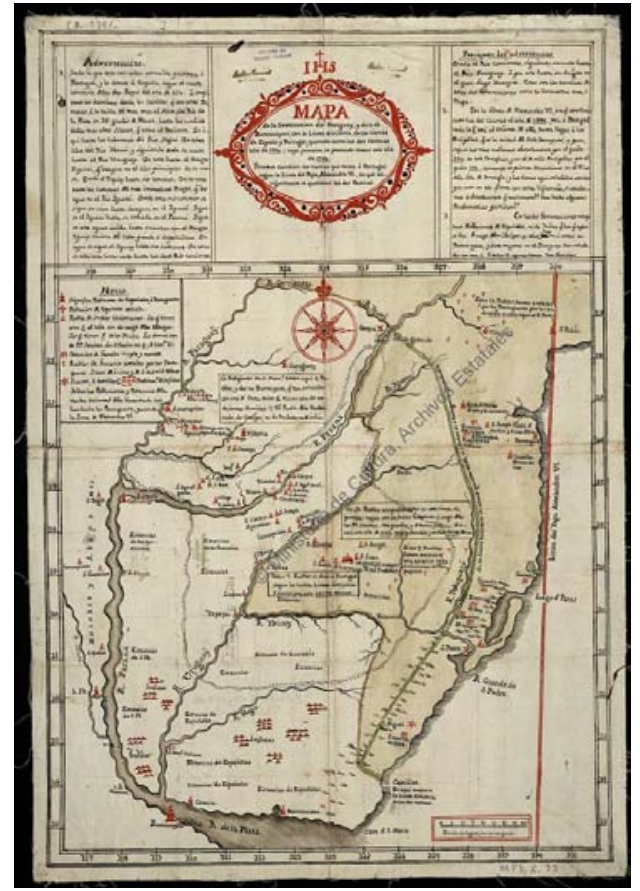

Fig. 8 Mapa de la propuesta jesuítica al Tratado de Madrid de 1750 (AGS, Signatura: MPD, 06, 032).

\footnotetext{
${ }^{58}$ BCS, Carta Anua 1735-1743, f. 256v.

${ }^{59}$ Cortesão, 1954b: 155.

${ }^{60}$ Pastells - Mateos, 1948, T. VII: 218.

${ }^{61}$ El P. Tomás Werler, ingresó a la provincia de Alemania Superior en 1708, dando sus primeros votos en Landsberg dos años después. Su sacerdocio fue conferido por el obispo Nieberlein en 1718 y sus últimos votos los profesó en Dillingen en 1723. Viajó al Paraguay en la expedición del P. Herrán de 1729, siendo destinado a las misiones (Storni, 1980: 310).

62 BCS, Carta Anua 1735-1743, f. 257.

${ }^{63}$ Regio Monteiro, 1937, T. 1: 236.

${ }^{64}$ Bucich Escobar, 1939: 37.
} 
de Madrid (1750) y la línea verde sobre el sombreado es la propuesta de los jesuitas, dejando para España los siete pueblos orientales. Recalcaron los jesuitas que con esta alternativa "ni a indios ni a portugueses perjudicaría”. Estos últimos desestimaron la pacífica intervención y se desató la guerra.

Pero después de esta contienda, Carlos III anuló el Tratado y ordenó al gobernador de Buenos Aires don Pedro de Cevallos la toma de Colonia. Reunió unos 5.000 soldados, de los que se contaban 1.200 guaraníes. Efectiva-mente el mandatario se dirigió al superior de las misiones P. Jaime Passino y le solicitó la presencia de dos jesuitas alemanes, los PP. Segismundo Baur (Baviera, 1719-1780) y Tadeo Enis (Bohemia, 1714-Cádiz, 1769) ${ }^{66}$. También acompañó en calidad de capellán el mencionado P. José Cardiel (Alava, 1704-Faenza, 1781) quien se encontraba reconstruyendo la reducción de San Miguel. Fue muy sufrida por el jesuita aquella intervención y su robusta salud jamás pudo recobrarla ${ }^{67}$.

Cuando fue convocado el P. Baur se encontraba en el pueblo de San Francisco de Borja y escribe una relación con los preparativos de los guaraníes que llevaría desde las reducciones. Se habían juntado todos en Ibirapitá-guazú, al sur de Yapeyú, de los cuales un grupo fue llevado por el P. Jaime Mascaró (Palma de Mallorca, 1717-Faenza, 1774), quien desde allí regresó a su reducción. Desde aquel enclave emprendieron la marcha con fríos, tormentas, lluvias y con la consecuencia de enfermos, desertores y muertos, llegando a Santo Domingo Soriano el 31 de agosto ${ }^{68}$. A las pocas semanas el bávaro le escribió a su compañero el H. Martínez:

"Colonia esta agonizando ya, y si los navíos españoles no se hubiessen retirado cobardemente ya sería de España. No perdimos hasta aora mas de dos hombres. Heridos no mortalmente tres. A dentro no dejaría de arder mas por los estragos que hicieron nuestros cañones" $\$$.

En otra carta que escribe al visitador P. Contucci le expresa que a su regreso viajó con 50 indios de San Javier y 50 de Santo Ángel: “desde que llegué a Santo Domingo Soriano se me murieron otros dos indios, y los bastantes enfermos que hay quedaron parados en dicho paraje". Agrega "ayer dieron las viruelas", aunque no se propagó $^{70}$.

El sitio se formalizó a fines de setiembre de 1762 y a mediados del mes siguiente la mayoría de los habitantes de Colonia pudieron evadir las fuerzas españolas y evacuar la población. Pero el 31 de octubre, el gobernador Vicente da Silva da Fonseca terminó capitulando y fue enviado a Río de Janeiro. Los portugueses retornaron con ayuda de Inglaterra para tomar el Río de la Plata y en enero de 1763 los españoles, en vista de la llegada del enemigo, abandonaron la plaza tras algunas escaramuzas.

Los guaraníes realizaron todas las obras militares requeridas para el sitio y el P. Paucke escribe un relato que le llegó por el boca del inglés Eduardo Poule, mozo al

\footnotetext{
${ }^{65}$ Lo publicó Furlong, 1936: 78. Original en Archivo General de Simancas. Signatura: MPD, 06, 032. De él se valieron el coronel José Custodio de Sá y Faria y el P. Tadeo Enis.

${ }^{66}$ Sierra, 1944: 206.

${ }^{67}$ Furlong, 1953: 46.

68 Trelles, 1882: 351- 370. (Original en AGN-BN. Doc. 4165).

${ }^{69}$ AGN, S. IX, 6-10-5, Doc. 494. Carta del P. Segismundo Baur al H. Miguel Martínez, 15 de octubre de 1762.

${ }^{70}$ Ibíd., Doc. 505, Carta del P. Segismundo Baur al P. Nicolás Contucci, Apóstoles, 24 de julio de 1762.
} 
servicio del comandante irlandés, quien residió en su reducción por un año, contándole que apenas fueron desalojados los portugueses, llegaron los ingleses bajo el mando del irlandés Mac Namara, en tanto que Cevallos se encontraba enfermo y los cañoneros estaban en Montevideo.

"Don Pedro corrió a los bastiones de la ciudad a los cañones, llevó consigo puros indios, les mostró cómo debían cargar los cañones, corrió desde uno al otro a dirigir los cañones y les ordenó dar fuego. Los indios se prestaron tan bien en esta artillería que atravesaron bonitamente con balas el buque inglés y a la vez voltearon a muchos ingleses en el buque”.

Agrega luego de otros pormenores que "Este disparar duró por algunas horas de ambos lados hasta que un indio acertó tan bien que él ha incendiado al buque con una bala ardiente. Ahí fue la perdición” y el buque se hundió.

Finalmente el 10 de febrero de 1763, se firmó el Tratado de París que puso fin a la Guerra de los Siete Años, y España tuvo que devolver los territorios conquistados. A fines de ese año Colonia volvía a manos portuguesas. Pero para ellos todo sucumbió en 1777 con la nueva y definitiva toma de Cevallos, cuando ya los jesuitas no se encontraban y a los mismos portugueses les dejó de interesar la plaza, sumando las órdenes del marqués de Pombal de no oponer resistencia.

\section{La nueva Colonia del Sacramento en tiempos de Vasconcelos.}

Volviendo al año 1717, recordemos que había que empezar todo de nuevo y el flamante gobernador Gomes Barbosa reconstruyó la plaza-fuerte "sem descubrir as antigas muralhas" "71. Se sumaron sesenta familias de colonos y la ciudad comenzó a prosperar como centro comercial y portuario, sobre todo a partir que asumió el gobierno el brigadier Antônio Pedro de Vasconcelos (1722-1749), quien favoreció en todos los aspectos a la comunidad, que ya alcanzaba el millar de habitantes y que se triplicó cuando dejó su mandato a Luis Garcia de Bivar. Con la llegada en 1723, del ingeniero militar Pedro Gomes Figueiredo, se reforzaron las murallas, especialmente el baluarte de San Pedro de Alcántara ${ }^{72}$. El profesional permaneció al menos hasta 1743 en que se pavimentó parte de la ciudad, levantaron la iglesia ante un fervor religioso evidenciado en la época, con la creación de numerosas hermandades como la del Santísimo Sacramento, la de Nuestra Señora del Pilar, la de Santa Ana, la de Nuestra Señora del Rosario, la de San Antonio y la de las Almas ${ }^{73}$.

Por su parte la residencia de los jesuitas, dependiente del colegio de Río de Janeiro, nuevamente abrió sus puertas en 1717. Quedó a cargo el profeso de cuarto voto P. Luiz de Andrade (Bahía, 1684-1753) y pronto comenzó a funcionar el colegio, con aulas de catequesis, primeras letras y humanidades ${ }^{74}$. A los dos años lo sucedió el

\footnotetext{
${ }^{71}$ Pereira de Sá, 1993: 54.

72 Trazó un plano de la fortificación en 1732, en cuyo margen izquierdo describe someramente los cambios que realiza de la ciudad.

${ }^{73}$ Azarola Gil, 1931: 100.

${ }^{74}$ Leite, 2004, T. II: 612.
}

74 Carlos A. Page. La presencia de los jesuitas en Colonia del Sacramento ... 56-87. 
sacerdote portugués P. António do Vale (Evora, 1674-Bahía, 1755), a quien en 1722 hubo que reemplazar por su excesiva fatiga en el gobierno de la casa ${ }^{75}$.

Un informe del gobernador expresaba que no solo era necesario aumentar el monto de manutención real, sino que dos jesuitas eran insuficientes, que hacían falta dos sacerdotes más y un coadjutor. El Consejo Ultramarino y luego el rey aprobaron el pedido, y en octubre de 1724 llegaron los dos nuevos jesuitas, cosa que motivó al gobernador a ordenar la ampliación del colegio, destinando fondos de la hacienda real para dos operarios pedreros y el suministro de piedras y tejas, mientras que la provincia jesuítica de Río de Janeiro aportaría las maderas, quedando una nueva sala para la enseñanza de los niños ${ }^{76}$.

El colegio quedó a cargo en 1722 del P. João Crisóstomo (Coimbra, 1683Bahía, 1753), quien había ingresado a la Compañía de Jesús de Brasil a los 18 años, alcanzando a profesar su cuarto voto en $1729^{77}$. Lamentablemente el P. João fue víctima de las injurias antijesuíticas de su tiempo, siendo acusado por el jesuita "renegado" Bento Pinheiro de Horta da Silva Cepeda en una escandalosa Relação escrita de su mano en 1761. Allí manifestó que muchos jesuitas eran auténticos empresarios que servían a su propio enriquecimiento, además de acusarlo de tener una hija. Justamente menciona al P. João:

“de colônia veio com grande cabedal, eposto no colégio da Bahia conservou até a morte as suas negociações, sendo correspondente de mercadores da colônia, que lheremetiam navios carregados à sua disposição, e ele à vista de toda a Bahia dava as providências necessárias para sedes carregar, dar saída aos gêneros, e carregar de fazenda aos navios. Teve também este padre na Colônia uma filha mulata, Paula, a qual estando ele já na Bahia, mandou buscar para casar comum mulato rico" ${ }^{78}$.

Gobernaba entonces el brigadier Vasconcelos quien desde 1722 favoreció el desarrollo de la nueva casa, recibiendo subsidios suyos y de particulares ${ }^{79}$. En 1725 el colegio alcanzó su plena prosperidad y el rey João V escribió al provincial de Brasil P. Gaspar de Faria alabando el celo de los sacerdotes. El edificio contaba con una sala para la enseñanza de los niños y otra nueva para el catecismo. Al fin, la Carta Anua escrita tres años después, describe el Colegio: "Escola para ensinar os Rudimentos, as Letras, $e$ os bons costumes. Faz-se a catequese dos escravos, e dos indios. Prega-se aos soldados para os contener nos seus deveres de cristãos, tanto na nossa Igreja como na Matriz, propondo-lhes a observancia dos Mandamentos”. Mientras que de la iglesia se

\footnotetext{
${ }^{75}$ El P. Antonio estudiaba filosofía cuando entró en la Compañía de Jesús de Portugal en 1692. En ese mismo año viajó a Brasil. Después de rector de Colonia de Sacramento lo fue del colegio de Belém de Cachoeira y luego del colegio de Bahía, ocupando también el cargo de vicerrector del noviciado de Jiquitaia desde 1735. Escribe Leite que tenía particulares “dotes de gobierno y de serenidad”, además de ser "Notável pela piedade e serenida de com que dissolvia as pequenas disidencias internas” (Leite, 2004, T.II: 214 y T. III: 451).

${ }^{76}$ Possami, 2006: 306.

77 Storni, 1980: 73.

${ }^{78}$ Relação sobre o deplorável estado a que chegou a Companhia nesta província do Brasil (Soriano, 1867: 325-349. Cit. Leite. 2000: 62).

${ }^{79}$ Leite, 2004, T. II: 612.
} 
dice que, gracias al aporte de Vasconcelos, se construyó una más grande de piedra y barro $^{80}$.

En aquel mismo año de 1722, el rey João V contrató a los PP. Joao Batista Carbone y Domingo Capassi (Nápoles, 1694-San Pablo, 1776) para el estudio de la astronomía de la Corte. Tiempo después fueron destinados a Brasil para elaborar mapas tendientes a conocer mejor el territorio y con ello mejorar la explotación de los recursos, aumentar la eficacia de la administración civil y eclesiástica, y frenar las pretensiones territoriales de otras potencias. Pero Cardone fue sustituido por el P. Diogo Soares (Lisboa, 1684-Minas de Goiás, 1748) y llegaron a las costas cariocas en febrero de $1730^{81}$. A pedido de los gobernadores de Río de Janeiro y Colonia del Sacramento, se trasladaron en octubre a esta última para efectuar mapas de la zona ${ }^{82}$. Capassi se volvió y Soares realizó tres trabajos cartográficos, entre observaciones astronómicas ${ }^{83}$.

El P. Soares informó al rey sobre el trabajo realizado y su opinión con respecto a la fortificación, ya que realizó un proyecto de nueva muralla mostrado en la planta de Colonia $^{84}$. Además muestra en dicha planta el sitio del colegio y alrededor del plano pequeñas perspectivas de los edificios principales, entre ellos el de la Compañía de Jesús, donde seguramente residió en sus días en Colonia (Fig. 9 y 10).

La disposición de esta iglesia es el caso que Nicolini llama: "una anomalía respecto del hábito que nos parece hoy normal de disponer una iglesia con sus "pies” hacia la plaza y no con su costado hacia ella" ${ }^{85}$. Pues durante los siglos XVI y XVII era lo habitual que así fueran construidas las iglesias, es decir con su lado lateral hacia la plaza. Esta "anomalía” ya se practicaba en la península Ibérica y fue tomada de los árabes y con la re-utilización de las mezquitas en iglesias enteramente góticas con su ingreso por una puerta lateral principal ubicada
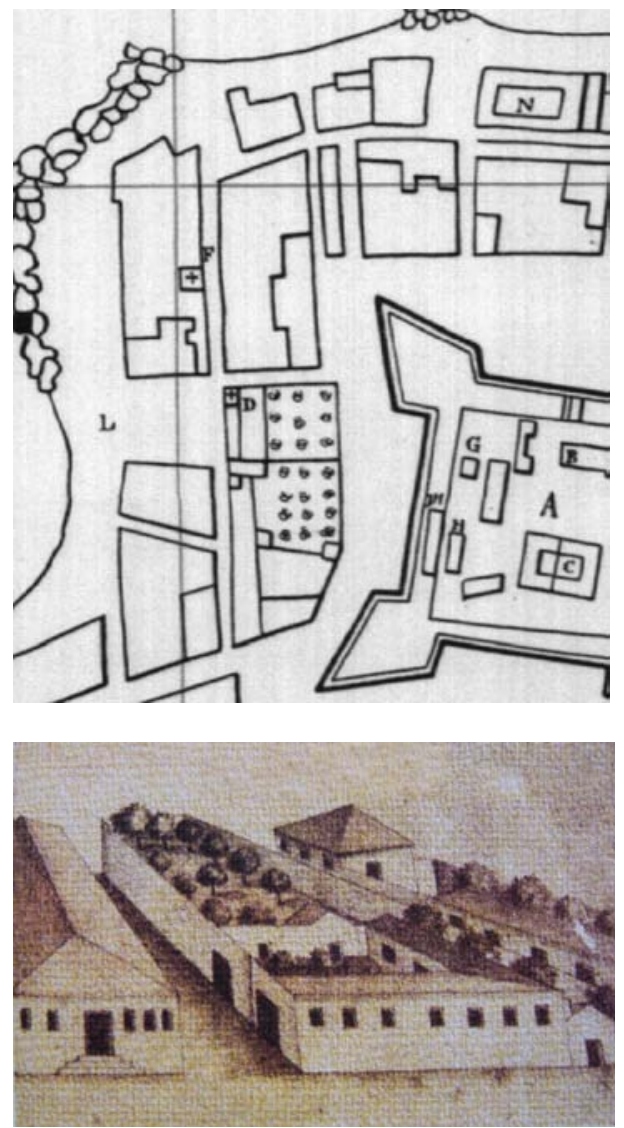

Figs. 9 y 10 Planta del edificio de la Compañía y perspectiva del mismo en el mapa del P. Diogo Soares de 1731 (Furlong, 1936: 13).

\footnotetext{
${ }^{80}$ Ibídem.

${ }^{81}$ Entre la bibliografía específica sobre el P. Soares cabe mencionar trabajos desde Leite, 1947, hasta Salas, 1994: 373-400.

${ }^{82}$ Possami, 2012: S199-S208.

83 A) “Grande Rio da Prata na America Portuguesa e Austral”, B) “Carta Topographica da Nova Colonia e cidade do Sacramento no Grande Rio da Prata” y C) Una planta de Colonia representando sus edificios, entre ellos el de la Compañía, ubicado frente a la fortaleza. La representación cuenta además con una serie de vistas de los edificios, encontrándose el del colegio de la Compañía.

${ }^{84}$ Carta del P. Diogo Soares al rey, Colonia do Sacramento, 27 de junio de 1731, en Regio Monteiro, 1937, T. 2: 80-82.

${ }^{85}$ Nicolini, 2001.
} 
hacia la plaza que, en el caso de Colonia, aparentemente no la tuvo.

Y la plaza que no es la principal, sino plazoleta, Plaza Menor o "plazoleta de respeto, es otro elemento urbano que se incorpora por esta época al trazado de Colonia en su apertura hacia el colegio jesuítico. En el plano de Soares figura como " $L$ " Porto del Coll., ubicada hacia el río. Mientras en otros mapas se denominará "Praça" o "Praia", siendo una extensión usada para facilitar el egreso de la iglesia y lugar donde estacionar caballos o carros. Aunque también tenía un uso simbólico en darle al templo perspectiva $^{86}$.

Como vimos, durante el mandato de Vasconcelos, Colonia soportó un sitio de 22 meses (1735-1736). Y si bien los portugueses recibieron ayuda a tiempo y Salcedo debió regresar a Buenos Aires, en el ataque los jesuitas perdieron la pequeña estancia que tenía el colegio, dirigido entonces por el P. José de Mendoça (Recife, 1686-Roma, 1760). La misma quedó destruida y su ganado robado y disperso $^{87}$. El P. Mendoça sucedió al Manuel Furtado (Bahía, 1680-1749) que estuvo en Colonia tres años, habiendo sido con anterioridad superior del colegio del Salvador ${ }^{88}$.

De aquel intento, el alférez del batallón de Colonia, Silvestre Ferreira da Sylva, profeso de la orden militar de Cristo, dio cuenta de los hechos en un libro publicado en Lisboa en 1748. Inserta un plano perspectivado (Fig. 11), a los fines de describir detalladamente el ataque y defensa portuguesa, señalando sus edificios. Sobresale el colegio de la Compañía de Jesús, con letra "S", pero sobre todo destaca su iglesia con una torre por detrás. Dentro de la "ciudadela" o fortaleza estaba la Iglesia Parroquial del Sacramento. Con la letra "R" la batería y capilla de Santa Rita; con la "T" la capilla de San Pedro Alcántara. Nótese que tampoco se señala a los franciscanos. Hacia la Bajada de Nazareth se encontraba la barraca del ya mencionado P. Tomás "Berly" (sic), "morto por huma bala da nossa artilharia, que lhetirou a vida en dia de S. Francisco Xavier" ${ }^{89}$.

El gobernador Vasconcelos debió reforzar su fortaleza como observamos en los

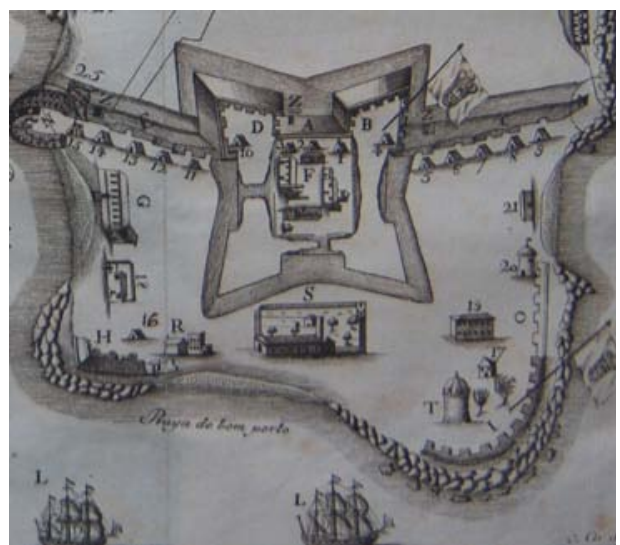

Fig. 11 Detalle de la iglesia del Colegio en 1735, publicado por Ferreira da Sylva.

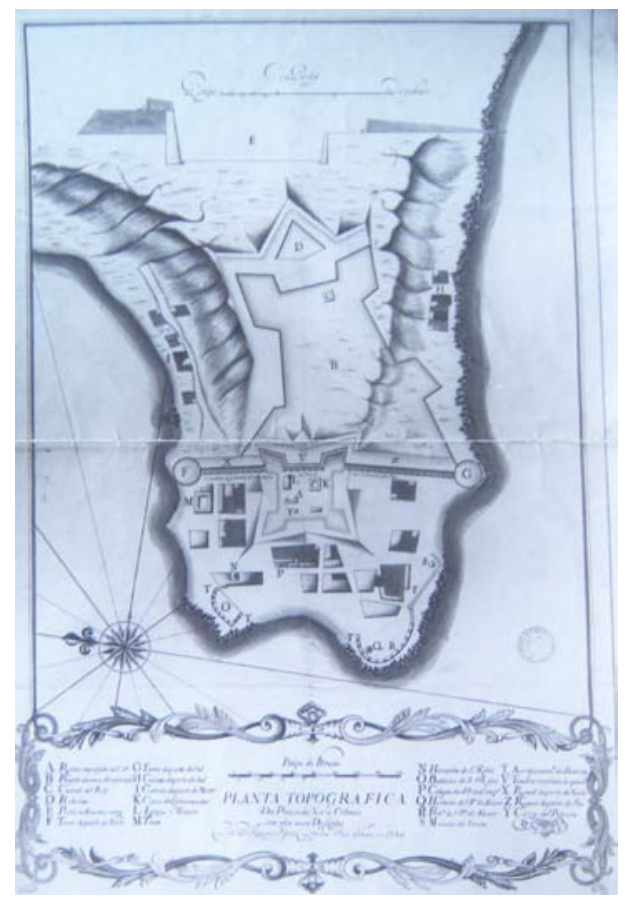

Fig. 12 Colonia do Sacramento del brigadier José de Silva Paes de 1736 (ARC).

\footnotetext{
${ }^{86}$ Page, 2008: 255.

${ }^{87}$ Leite, 2004, T. II: 612-613.

${ }^{88}$ Ibíd., T. II: 266 y Storni, 1980: 108.

${ }^{89}$ Ferreira da Silva, 1748: 99.
} 
proyectos no concretados del brigadier José da Silva Paes en 1736 (Fig. 12) y la del monje benedictino Frei Estevão do Loreto Joassar (Fig. 13). En este último se ubica la Iglesia Matriz dentro de la fortaleza, la ermita de Santa Rita (“H”) en la misma calle de los jesuitas (“G”), la ermita de San Pedro Alcántara en la batería del mismo nombre. En ambos mapas se ubica el Colegio jesuítico con su iglesia de lado y frente a una plazuela.

Del ataque de 1735, los jesuitas no pudieron reponerse, continuando con una desesperada situación en 1743. A pesar de todo perseveraron dos jesuitas para el socorro espiritual de los moradores de Colonia. En este periodo estuvieron de rectores el mencionado $\mathrm{P}$. José Mendoça, quien fue sustituido por el P. Manoel Pimentel en 1738 (Oporto, 1701-iं?). Fecha en que después de dos años de estadía en Colonia, el P. Andrés de Cunha (Santos, 1696¿?) dejó los hábitos y se desconoce su paradero $^{90}$.

Para 1737 Simaõ Pereira de Sà escribió que Colonia contaba con 350 vecinos, una iglesia matriz, "hum Colegio da Companhia”, además del hospicio de Capuchinos y dos capillas, la de Santa Rita y la de San Pedro de Alcántara. Pero también extramuros se encontraban los templos de Nuestra Señora de la Concepción, Nazareth, Oliveira y Rosario. Un poco más adelante habla de los "terreiros" que era justamente la plazuela ubicada frente a la iglesia de la Compañía y la futura Plaza Mayor $^{91}$.

El viaje del P. Florián Paucke (Silesia, 1719-Bohemia, 1779), realizado desde Europa fue detalladamente descripto, como en cierta forma también lo hizo el P. Martín Dobrizhoffer $^{92}$ (Bohemia, 1718-Viena, 1791), pues viajaron juntos. El primero menciona que llegó a Colonia del Sacramento a fines de 1748 con el procurador en Europa Ladislao Orosz. En ese año estaba dejando el cargo de rector el P. Silvério Pinheiro (Lisboa, 1711-i?) y

\footnotetext{
${ }^{90}$ Storni, 1980: 75.

${ }^{91}$ Pereira de Sà, 1993: 58.

${ }^{92}$ Dobrizhoffer, 1967, V. 1: 6-8.
}

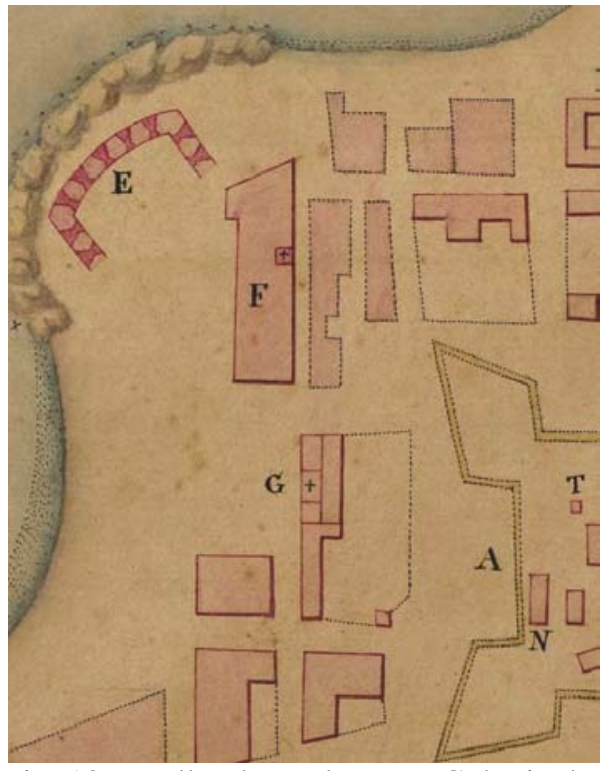

Fig. 13 Detalle Planta da Nova Colonia do Sacramento tirada en 1737 “G” Collegio y "F" Capilla de Santa Rita, del benedictino fray Estevão do Loreto Joassar de 1737. (BNB).

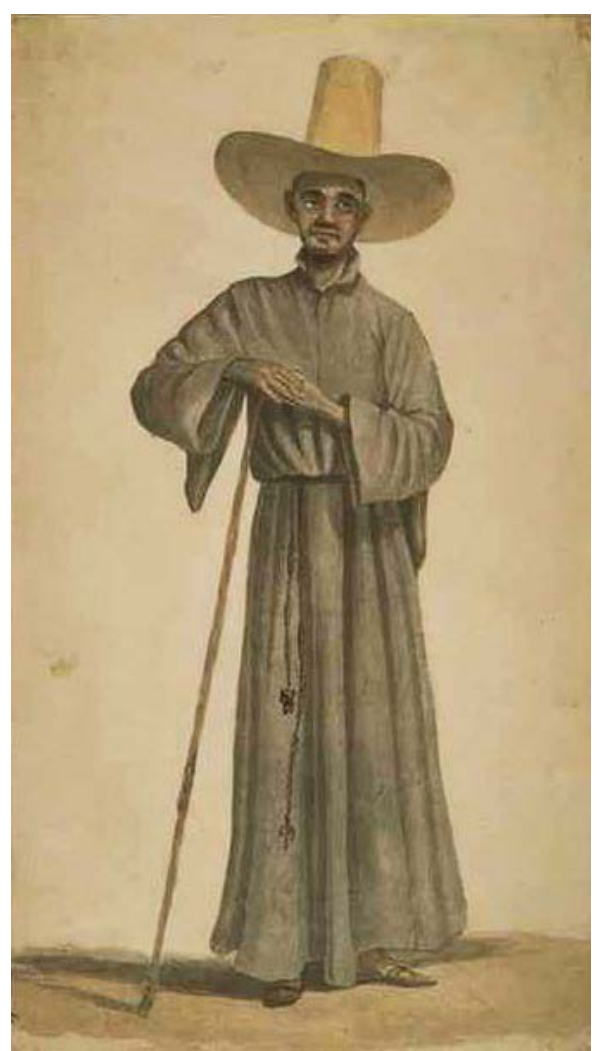

Fig. 14 Un sacerdote jesuita en Brasil con la usanza de entonces: sombrero de ala ancha y bastón. Pintura de mediados del siglo XVIII. 
asumiendo el P. Francisco Ferraz (Río de Janeiro, 1706-Capitanía, Brasil, 1757). Para esa época llegaron a Colonia los PP. Francisco Ferreira (Braga, 1710-Rio de Janeiro, 1758) e Ignacio Antunes (Recife, 1716-Roma, 1761). Ambos profesaron su cuarto voto en Colonia; el primero en 1746 y el segundo en $1750^{93}$ (Fig. 14).

El P. Florián relata que partieron de Lisboa el 20 de setiembre de 1747, llegando en Navidad a Montevideo, donde el P. superior envió un mensaje a su par de Colonia avisando sobre el esperado arribo e informando que el contingente se dirigía para allá. Alguna dificultad tuvieron en la travesía por el Río de la Plata donde los bancos de arena y tormentas asediaron al navío. Pero por fin el 27 de diciembre avistaron un bergantín de Colonia que les acercó alimentos que enviaba el superior de la residencia P. Pinheiro, y los ayudó a llegar al puerto, donde bajaron anclas el 29 a la tarde. Relata el P. Paucke que en la residencia de los jesuitas portugueses se encontraban seis sacerdotes:

"Todos desembarcamos con regocijo, fuimos en parejas a la iglesia grande donde el Te Deum/ fue cantado con música tras lo cual nos presentamos al Gubernator, le agradecimos el cuidado recibido; después nos trasladamos todos a la residencia donde ya nos esperaban con un magnífico almuerzo portugués por el cual todos los orantes de nuestro buque abandonado fueron introducidos a la Residencia”.

Luego de describir detalladamente la ciudad, el $1^{\circ}$ de enero llegó el barco que los transportó a Buenos Aires, donde los aguardaba el provincial Manuel Querini ${ }^{94}$.

Obviamente con el Tratado de Madrid del 13 de enero de 1750 todo se empeoró, aunque como la entrega no fue inmediata los jesuitas portugueses reorganizaron su estancia quedando a la expectativa de los acontecimientos ${ }^{95}$. Por cierto, que así como los guaraníes debieron abandonar sus pueblos, los habitantes de Colonia no lo hicieron y todo quedó sin efecto. En 1751 asumió como rector el P. Antonio Simões (Coimbra,

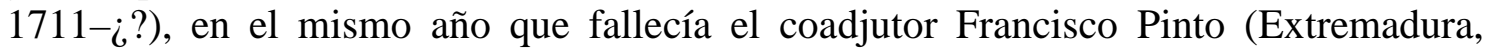
Portugal, 1725-Colonia, 1751).

\section{La expulsión de los jesuitas de Portugal.}

Sebastião José de Carvalho e Melo (marqués de Pombal y futuro conde de Oeiras) fue la figura y motor central de la expulsión de los jesuitas de los dominios lusitanos en su calidad de primer ministro de José I. Con amplios poderes, comenzó una política regalista a la que se opusieron los ignacianos. Desde el Tratado de Límites de 1750 las diferencias se acentuaron y se acusó a los jesuitas de instigar la sublevación guaraní en defensa de sus tierras.

A partir de entonces se acentuó una campaña antijesuita con toda clase de líberos, extendiéndose a Roma, donde se adhirió a los pedidos portugueses de depurar el Instituto. Pero el fallido atentado a José I (3 de setiembre de 1758) selló lo que se venía pergeñando, pues se acusó a los jesuitas de ser los instigadores del regicidio, y de paso se sacaron de encima elementos de la nobleza que molestaban. En la oportunidad se

\footnotetext{
93 Storni, 1980: 100 y 16.

${ }^{94}$ Page, 2007: 316.

${ }^{95}$ Leite, 2004, T.II: 613.
} 
involucró al anciano jesuita Gabriel Malagrida, antiguo misionero del Brasil, quien murió estrangulado y su cuerpo fue quemado en la plaza del Rossio de Lisboa, en un auto de fe presidido por el inquisidor, hermano de Carvalho (Fig. 15).

De tal forma que el 19 de enero de 1759 se promulgó en principio la confiscación de bienes y confinamiento de los jesuitas, pero el 3 de setiembre de ese año se decretó la expulsión de los dominios portugués y poco más de un millar de jesuitas fueron exiliados a los Estados Pontificios.

La provincia jesuítica de Brasil expulsó a 443 religiosos entre setiembre de 1759 y abril de 1760. De ellos, 144 dimitieron al Instituto, un número considerable que demuestra el alto grado de presión que ejercieron las autoridades para que tomaran esa decisión.

A fines de 1759 en Lisboa, estarían preparadas tres naves de guerra para partir a Brasil en busca de los jesuitas ${ }^{96}$. Llegaron al puerto de Bahía y una de

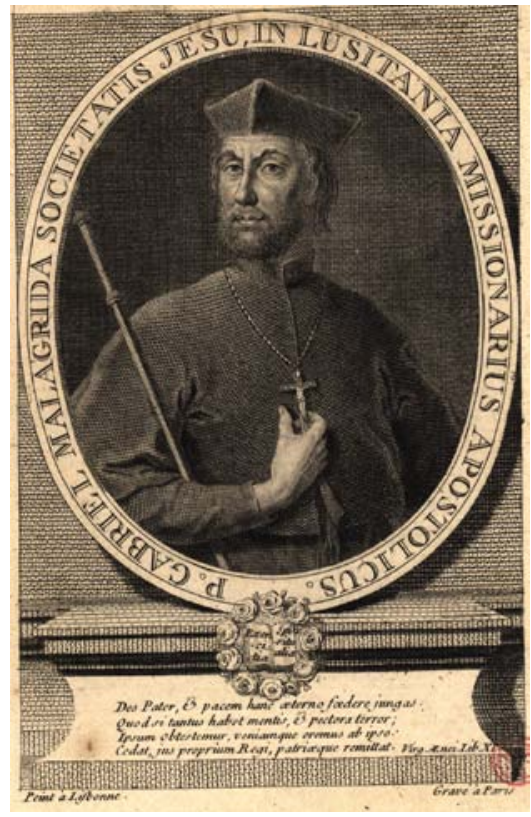

Fig. 15 Grabado del P. Malagrida, en la hoguera del auto de fe de la plaza Rossio, el 21 de setiembre de 1761 (París c.1761-1777) (BNP). ellas partió con rumbo a Río de Janeiro donde se concentraron los jesuitas de la región sur, que llevaban allí cinco meses de espera. La nave "Nossa Señora do Livramento e São José”, llegó a destino el 24 de enero de 1760 y su comandante Gaspar Pinheiro entregó las órdenes de la expulsión al gobernador Gomes Freire de Andrade. Allí se encontraban 145 religiosos de los cuales 26 dimitieron, siendo embarcados finalmente 119 que partieron de Río de Janeiro con rumbo a Lisboa el 16 de marzo de 1760. Hacinados en la bodega, muchos enfermaron y uno murió, alcanzando las costas lusitanas el 6 de junio ${ }^{97}$. Fue la primera embarcación que llegó de Brasil y sin pisar tierra fueron trasladados al barco de bandera genovesa "San Francisco de Paula". En ella embarcaron al resto de los jesuitas y pasaron a navegar por el Mediterráneo hasta alcanzar el puerto romano de Civitavecchia. Llegaron 265 religiosos de Brasil, el 30 de julio de 1760 .

La única lista publicada existente de los jesuitas expulsados de América portuguesa es la que elaboró el P. José Caeiro (1712-1791). Escribió sobre los sucesos relativos a la expulsión de los jesuitas de los dominios lusitanos, desde que fueron arrestados a fines de 1758 hasta el exilio en Italia. A fines de 1764 concluyó su obra "De exilio" compuesta de dos partes, una sobre lo acaecido en Portugal y otra en los dominios ultramarinos. La primera fue publicada en tres volúmenes entre 1991 y 1999. La otra, referida a Brasil y la India se publicó una edición bilingüe en $1936^{98}$. La lista

\footnotetext{
${ }^{96}$ Las naves de referencia eran Nossa Señora de Ajuda e São Pedro de Alcántara, comandada por Antonio Brito Freire; Nossa Senhora do Monte Carmo, al mando del capitán teniente Bernardo de Ferreira e Abreu; y Nossa Señora do Livramento e São José, capitaneada por Gaspar Pinheiro de Camara Manuel. Además los jesuitas poseían una nave con el nombre de e São José que fue confiscada en el puerto fluminense (García Arenas, 2013: 8).

97 Ibíd.: 11.

${ }^{98}$ Caeiro, 1936.
}

80 Carlos A. Page. La presencia de los jesuitas en Colonia del Sacramento ... 56-87. 
desordenada la reorganizó Edgar Leite, que nos brinda información sobre algunos de los jesuitas que estuvieron en Colonia del Sacramento, quienes fueron deportados juntos con los de la isla de Santa Catarina ${ }^{99}$.

Para la expulsión de los jesuitas de Portugal se encontraba como rector en Colonia el P. António Galvão (Coimbra, 1703-¿'), que se hallaba desde 1738, habiendo profesado sus últimos votos en 1740 y sucediendo al P. Simões, arrestado en el colegio del Espíritu Santo, junto al P. Pinhelo, también ex rector en Colonia. Del P. Galvão se refirió el mencionado renegado Bento de Cepeda en 1761, escribiendo que: "teve grosso negócio em courama e outros generoscom os castelhanos... o chamavam vulgarmente de o mundo e o fundo..."100. Igualmente el P. Galvão fue conducido con su compañero a Río de Janeiro y sus papeles quemados ${ }^{101}$. Era el P. Pedro Barreiros (Rio de Janeiro, $1724-\dot{¿}$ ?) quien profesó sus últimos votos en Colonia en $1757^{102}$. Ambos dimitieron en Rio de Janeiro, de allí que no conozcamos su paradero.

De los religiosos que estuvieron en Colonia sabemos que llegaron a Italia los P. José Mendoça ${ }^{103}$, Manuel Amaro ${ }^{104}$ e Ignacio Antunes ${ }^{105}$, pero al poco tiempo fallecieron en Roma. Mientras que el P. Francisco Ferreira falleció en Río de Janeiro y Manuel Pimentel que se encontraba en el colegio de São Pablo, no viajó a Europa y falleció en Rio de Janeiro en 1769, por lo que quizás también haya sido uno de los que abandonaron el Instituto. Recordemos que el visitador P. Almeida, viendo las condiciones deplorables en que se encontraban los jesuitas, los inducía a una deserción simulada ${ }^{106}$.

Regio Monteiro escribe que: “A expulsão dos Jesuitas que existiam na Colônia, bem como em todo o Brasil, veio causar perturbasões, não só em sua vida religiosa, como também na instruçõe pública que por éle era administrada; em escolas públicas e particulares”. Por esos motivos el obispo Antônio do Destêrro designó, por provisión del 2 de febrero de 1760 al P. Manuel Fernandes da Silva, nacido en Colonia, para el cargo de maestro de primeras letras y gramática "de acôrdo com o novo metodo que Sua

\footnotetext{
${ }^{99}$ Leite, 2000: 154.

${ }^{100}$ Relação sobre o deplorável estado a que chegou a Companhia nesta província do Brasil (Soriano, 1867, T. II: 325-349, Cit. Leite, 2000: 62).

${ }^{101}$ Leite, 2004, T. II: 613.

102 Storni, 1980: 31.

103 El P. Mendoça era como dijimos de Recife. Fue superior en la vila de Tapuitapera (AlcântaraMaranhão), luego rector del Colegio de Nossa Senhora da Luz de São Luis de Maranhão (1724-1727), y vice provincial de Maranhão (1727). Después fue a Colonia “donde prestó relevantes servicios”. Luego fue rector del Seminario de Belém de Cachoeira y del Noviciado de Jiquitaia (2 veces). Se encontraba en Bahía cuando fue deportado en 1760 y de allí llevado a Lisboa y luego Italia, falleciendo en Roma (Leite, 2004, T. III: 349).

${ }^{104}$ El P. Amaro nació en Oporto en 1679, ingresando a la Compañía de Jesús a los 17 años. Profesó su cuarto voto en San Pablo en 1718, siendo luego superior de la casa de Paranaguá. Luego de permanecer en Colonia entre 1726 y 1729, fue designado rector del Colegio de Santos donde permaneció hasta ser deportado a Río de Janeiro y de allí a las cárceles de Azeitäo en Portugal para finalmente pasar a Italia y morir en Roma en 1761 (Storni, 1980: 11 y Leite, 2004, T. III: 202 y IV: 394, 568 y 578).

${ }^{105}$ Como dijimos el P. Antunes era de Recife, al igual que el P. Mendoça e ingresó al Instituto en 1730. Al tiempo de la expulsión se encontraba en el Colegio de Río de Janeiro y llevado preso a la isla de las Cobras con doble grillete (Leite, 2004, T. III: 219).

${ }^{106}$ AGI, 1852, T. 1: 125.
}

81 Carlos A. Page. La presencia de los jesuitas en Colonia del Sacramento ... 56-87. 
Magestade mando u praticar”. Le entregó el inmueble de los jesuitas y sus pertenencias ${ }^{107}$ y comenzó a enseñar hasta su muerte acaecida en $1766^{108}$.

Por su parte la huerta de los jesuitas fue rematada el 18 de marzo de 1759 a José Francisco Lessa por la suma de $190 \$ 000^{109}$ a pagar en un plazo de seis meses, y el 20 de junio del mismo año se remató por $40 \$ 000$ a Francisco Pedro Bitencourt una chacra de los jesuitas a pagar en un año. Dos años después la quinta fue arrendada a Manoel Gomes do Santos en 33\$000 anuales y para 1772 a José Félix Correa en 32\$000, mientras que la huerta a Manoel Antonio da Costa en $61 \$ 000$ para el año $1765^{110}$ (Fig. $16)$.

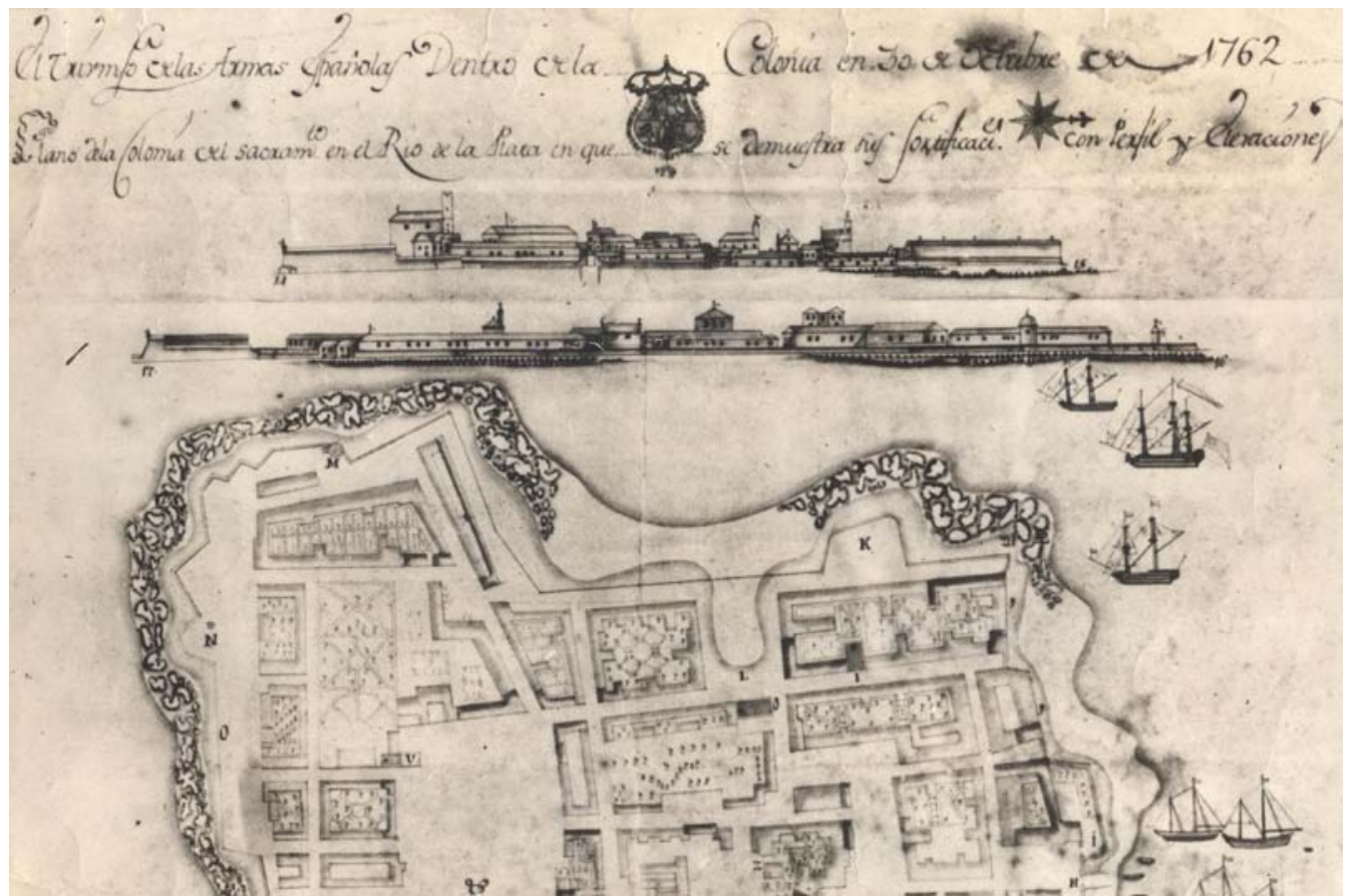

Fig. 16. Mitad posterior del mapa titulado "El triunfo de las armas españolas dentro de la Colonia el 30 de octubre de 1762". Con "L” "Plaia del Colegio sin muralla adelante” y “Ó” "Colegio que fue de los jesuitas" (AGN).

Con respecto al destino de los edificios, el mismo Cevallos para su primera invasión se justifica expresando que: "Ia Iglesia principal está poco decente y sumamente pobre de altares, alajas, y ornamentos, y otros dos oratorios que hay en dos residencias uno delos Franciscanos, y otro que fue de los jesuitas, son extremaamente reducidos, y mui pobres". De este último "no me atrevo á tomar providencia alguna hasta saber la voluntad de SM, y solo pienso entretanto hacer que vengan algunos Misioneros dela misma religión" ${ }^{111}$.

\footnotetext{
${ }^{107}$ Regio Monteiro, 1937, T. 1: 305.

108 Rubert, 1994: 48.

109 Así se representaba la moneda Conto de Réis, utilizada desde tiempo del Imperio hasta 1942 que apareció el Cruzeiro.

${ }^{110}$ Regio Monteiro, 1937, T. 2: 220-221-222-223.

${ }^{111}$ AGI, Buenos Aires 538, Carta de Cevallos a SM, Colonia del Sacramento, 15 de noviembre de 1762.
} 
Con la segunda invasión de Cevallos de 1777 -afirma Regio Monteiro- se destruyeron las murallas y baluartes, además de viviendas, casa de gobierno, almacén real, hospital de los capuchinos y el colegio de los jesuitas, entre otros edificios no menos importantes. Solo se dejó en pie una pequeña casa para un destacamento, la iglesia parroquial, y las capillas de los franciscanos y de Nuestra Señora del Carmen ${ }^{112}$. El párroco Pedro Pereira Fernandes de Mesquita dejó una relación de lo acontecido en junio de 1778. Cuenta que Cevallos mandó a demoler la ciudad, aunque la misma no fue ejecutada totalmente.

El teniente coronel don Sebastián de Palomar tuvo a cargo la destrucción. Los muebles y enceres de los portugueses fueron trasladados a Buenos Aires. Los techos y muros de las viviendas fueron demolidos en su mayor parte. Pero como dijimos, las iglesias se dejaron intactas, aunque la profundización de su deterioro las llevó a su fin. Las respetadas por Cevallos -insiste Azarola Gilfueron "la Mayor, la del Carmen y la de la Orden Tercera" ${ }^{113}$. Es decir que ya nada quedaba del colegio jesuítico.

En el año 1777 se ordenó un inventario de las iglesias de los franciscanos, la iglesia mayor, iglesia del Carmen y la de los jesuitas no se menciona. Sumado al plano que los portugueses levantaron ese mismo año, no figura la iglesia sino "Colegio". Después de la destrucción y en el plano que publica Capurro de 1805-1806 (Fig. 17) no se señala ni plazoleta, ni iglesia, ni colegio, porque ya no había quedado nada, solo se menciona el nombre de la calle "Del Comercio"114, como hoy sigue llamándose. Igualmente en la Basílica del Santísimo Sacramento se encuentran dos tallas misioneras, una de San Francisco Javier y otra del Arcángel San Gabriel, además de una pintura de San Miguel Arcángel. Es muy posible que esas imágenes hayan pertenecido a la desaparecida iglesia de los jesuitas.

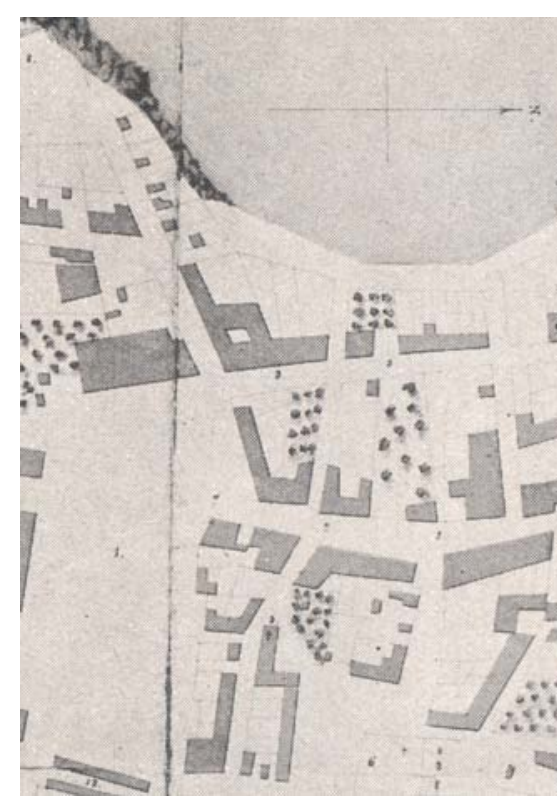

Fig. 17 Detalle del plano que publica el arquitecto Capurro, realizado entre 1805-1806. Con el número 9 se señala "vestigios de la iglesia del Carmen y de Santa Rita”.

\section{Palabras finales.}

El trabajo de los jesuitas portugueses en Colonia del Sacramento no se limitó solo a ser capellanes de milicias, sino que se hicieron cargo de la educación de los jóvenes, atendieron en ciertas épocas la parroquia y suministraron los sacramentos a una variada conformación demográfica que incluía blancos, esclavos e indios. Con estos últimos fueron muy claras las Instrucciones de 1678 al fundador, con respecto a que debían reducir a los naturales en poblados. Lo intentaron los jesuitas lusitanos con los minuanes, pero no tuvieron el éxito esperado.

\footnotetext{
112 Ibíd., T. 1: 451.

${ }^{113}$ Azarola Gil, 1931: 137-138.

${ }^{114}$ Capurro, 1928: 95.
} 
El entusiasmo fundacional de los PP. Pedroso y Alvares con su iglesia y residencia de San Pedro y San Pablo quizás solo se repitió en 1717 cuando se abrió nuevamente pero esta vez con la categoría de colegio y con el nombre de San Francisco Javier, bajo los rectorados de los PP. Andrade, do Vale y especialmente Crisóstomo. También se amplió la iglesia con el apoyo del gobernador Vasconcellos. Pero ya no será aquella tipología típicamente portuguesa de los inicios, sino simplemente un edificio de una sola nave con techo a dos aguas de la que no conocemos mayores detalles. Aunque sabemos que se presenta construida de lado a una flamante Plaza Menor que alude a características urbanas de influencias hispano-mudéjar.

El colegio se desarrollaba en una amplia manzana rectangular, donde tenía su huerta y en las afueras una estancia para ganado, pues la corona le proporcionaba alimentos y dinero.

A cada ataque de los españoles seguía la demolición de sus edificios como manera de borrar su memoria y con ello también la quema de la documentación del colegio como de las demás instituciones. Frente a este panorama, los guaraníes fueron protagonistas obligados y seguramente los que más perdían. Pues al dejar las reducciones sin hombres, se dificultaron las tareas cotidianas, sobre todo en lo referente a la alimentación. No pocos huían y morían de hambre en los campos, lo cual trajo pestes a los pueblos hambreados. Aparte la corona española no les pagaba estipendio alguno por los servicios que prestaban, que en algunos casos llegaban a soportar casi dos años en guerra. Hasta llevaban sus propios alimentos y los que le proveían a los españoles. Por tanto en esta guerra ajena a sus intereses, no es casual que en todos los sitios los guaraníes comercializaran con los portugueses, aunque les costara la vida. Los jesuitas eran conscientes de todas estas circunstancias y en todo momento se enorgullecían de la fidelidad al rey que tenían los guaraníes cristianizados.

Ochenta años con interrupciones, a veces de una década, fue el paso de los jesuitas portugueses por Colonia del Sacramento. Caer para volver a empezar, como todos sus habitantes, que como corolario se les arrancó gran parte de su historia y en definitiva su identidad que fue y es siempre, el gran trofeo de los vencedores.

\section{Referencias}

\section{Archivos}

AGI. Archivo General de Indias, Sevilla.

AGN, Archivo General de la Nación Argentina, Buenos Aires.

AGS, Archivo General de Simancas.

ANCh, Archivo Nacional de Chile, Santiago.

ARC, Archivo Regional de Colonia del Sacramento

BCS, Biblioteca del Colegio del Salvador, Buenos Aires.

BNB, Biblioteca Nacional de Brasil, Río de Janeiro.

BNP, Biblioteca Nacional de Portugal. Lisboa. 


\section{Bibliografía}

AGI. (1852), Anecdotas do ministerio do Marquez de Pombal e conde d'Oeiras, Sebastião José de Carvalho, sobre o reinado de D. José I, rei de Portugal. Porto: Domingos Pereira da Silva Ed., Tomo I.

Azara, D. Félix de (1847), Decripción e historia del Paraguay y del Río de la Plata, Tomo I, Madrid: Imprenta de Sánchez.

Azarola Gil, Luis Enrique (1931), Contribución a la historia de Colonia de Sacramento. La epopeya de Manuel Lôbo, seguida de una crónica de los sucesos desde 1680 hasta 1828 y de una recopilación de documentos. Madrid-Buenos Aires: Compañía Ibero-Americana de Publicaciones.

Bucich Escobar, Ismael (1939), Campaña Brasil. Antecedentes coloniales. Tomo 2 1750-1762, Buenos Aires: Archivo General de la Nación.

Caeiro, Padre José (1936), De Exilio ProvinciarumTransmarinarum - Jesuitas do Brasil e da India na perseguição do Marquês de Pombal. Rio, ABL, Com a tradução portuguesa de Manuel Narciso Martins, introdução de Luis Gonzaga Cabral e Nota Preliminar de Afrânio Peixoto. Baia.

Capurro, Fernando (1928), La Colonia del Sacramento, Montevideo: Sociedas “Amigos de la arqueología”.

Charlevoix SJ, Pedro Francisco Javier de (1913), Historia del Paraguay, Madrid: Librería de Victorino Suárez, T. IV.

Correa Luna, Carlos (1931), Campaña del Brasil. Antecedentes coloniales, Tomo 1 (1535-1749), Buenos Aires: Archivo General de la Nación y Ed. Kraft Lda.

Cortesão, Jaime (1954a), Tratado de Madri. Antecedentes. Colonia do Sacramento (1669-1749), Río de Janeiro: Biblioteca Nacional.

Cortesão, Jaime (1954b), “O territorio da Colonia do Sacramento e a formação dos estados platinos”, Revista de História, São Paulo, 5, 17, enero - marzo.

Da Costa Regio Monteiro, Jonathas (1937), A Colonia do Sacramento 1680-1777. Porto Alegre: Livraria do Gôbo, T. 2.

Dobrizhoffer SI, Martín (1967), Historia de los abipones, Santa Fe: Imprenta de la Universidad Nacional del Litoral, Vol. 1.

Ferreira da Silva, Silvestre (1748), Relaçao do sitio que o governador de Buenos Aires don Miguel de Salcedo poz no anno de 1735 a praça da Nova Colonia do Sacramento.

Furlong SJ, Guillermo (1936), Cartografía jesuítica del Río de la Plata, Buenos Aires: Facultad de Filosofía y Letras.

Furlong SJ, Guillermo (1942), Médicos argentinos durante la dominación hispánica, Buenos Aires: Ed. Huarpes.

(1944), Historia del Colegio del Salvador y de sus irradiaciones culturales y espirituales en la ciudad de Buenos Aires, Buenos Aires: Colegio del Salvador, T. I.

(1953), José Cardiel y su carta Relación (1747), Buenos Aires: Librería del Plata. 
(1978), Misiones y sus pueblos de guaraníes, Posadas: Lumicop.

García Arenas, Mar (2013), “Los antecedentes de un exilio: la expulsión de los jesuitas de Brasil y su llegada a los estados pontificios (1759-1760)”, Trocadero, $\mathrm{n}^{\circ} 25$.

González, Hno. Silvestre (1966), Diario de viaje a las vaquerías del mar (1705), Presentado por Baltasar Luis Mezzera, Montevideo: Artes Gráficas Covadonga.

Hernández SI, Pablo (1913), Organización social de las Doctrinas, Barcelona: Gustavo Gili ed. T. II.

Leite SJ, Serafim (1947), “Diogo Soares, S.I.: Matemático, Astrónomo, e Geógrafo de Sua Majestade no Estado do Brasil (1684-1748), Brotéria, Vol XLV, Lisboa Paulo, 4 V. (2004) [1938-1950], História da Companhia de Jesus no Brasil, São

Leite, Edgard (2000), "Notórios rebeldes”. A expulsâo da Companhia de Jesus da América portuguesa”. En José Andrés-Gallego (coord..)Impacto en América de la expulsión de los jesuitas, Madrid: Fundación Histórica Tavera y Fundación Hernando de Larramendi.

Levinton, Norberto (2009). El espacio jesuítico-guaraní. La formación de una región cultural. Asunción: Centro de Estudios Antropológicos de la Universidad Católica.

Marotta Castro, Wilde E. (2000), Los indios mansos de la Banda Oriental. Santo Domingo Soriano-Documentada, Montevideo: Impresora Editorial.

Nicolini, Alberto (2001), "Perduración de rasgos y anomalías en la ciudad hispánica cuadricular de Tucumán y Cuyo". En: XI Congreso nacional y regional de historia argentina, Córdoba: Academia Nacional de la Historia.

Page, Carlos A. (2007), Los viajes de Europa a Buenos Aires según las crónicas de los jesuitas de los siglos XVII y XVIII, Córdoba: Báez Ediciones.

(2008), El espacio público en las ciudades hispanoamericanas. El caso de

Córdoba (Argentina). Siglos XVI a XVIII, Córdoba: Junta Provincial de Historia.

Pastells SJ, Pablo (1918-1933), Historia de la Compañía de Jesús de la Provincia del Paraguay (Argentina, Paraguay, Uruguay, Perú, Bolivia y Brasil) según los documentos originales del Archivo General de Indias, Madrid: Librería General de Victoriano Suárez, T. III-V.

Pastells SJ, Pablo y Mateos SJ, F. (1948), Historia de la Compañía de Jesús de la Provincia del Paraguay, Madrid: Consejo Superior de Investigaciones Científicas, T. VII.

Pereira de Sá, Simão (1900), Historia topographica e bellica da Nova Colonia do Sacramento do Rio da Prata. (Este último fue escrito entre 1737 y 1750 y recién impreso en 1900 por el Lycêo Litterario Portuguez. Una reciente edición en Porto Alegre: Arcano 17, 1993).

Possami, Paulo César (2006), A vida quotidiana na Colónia do Sacramento (17151735), Lisboa: Editoria Livros do Brasil.

(2012), “A Colônia do Sacramento vista pelos viajantes (século XVIII)”, Estudos Ibero-Americanos, Porto Alegre, v. 38, supl. nov. 
Relação sobre o deplorável estado a que chegou a Companhia nesta província do Brasil. in Soriano, Simão José da Luz: História do Reinado de El-Rei D. José e da administração do Marquês do Pombal. Tomo II. Lisboa, Universal, 1867.

Riveros Tula, Aníbal M. (1959), Historia de la Colonia del Sacramento (1680-1830), Montevideo: Revista del Instituto Histórico y Geográfico del Uruguay, N ${ }^{\circ}$ XXIII.

Rodrigues SJ, Antonio (1695), Atestado sobre o que Jerónimo Bueno dissera ao morrer sobre partilhas, Säo Pablo, 7 de decembro.

Rubert, Arlindo (1994), História da Igreja no Rio Grande do Sul, Rio Grande do Sul: EDIPUCRS!?

Salas, Dalton (1994), "Diogo Soares: cartógrafo e arquitecto”, Anais do X Simpósio Nacional de Estudos Misssioneiros, Santa Rosa.

Santos, Paulo F. (1963), "Contribuicao ao estudo da arquitectura da Companhia de Jesusem Portugal e no Brasil”. Coimbra; Actas do V Coloquio Internacional de Estudos luso-Brasileiros. Coimbra.

Sierra, Vicente D. (1944), Los jesuitas germanos en la conquista espiritual de HispanoAmérica, Buenos Aires: Facultad de Filosofía y Teología.

Soriano, Simão José da Luz (1867), História do Reinado de El-Rei D. José e da administração do Marquês do Pombal. Tomo II. Lisboa: Universal.

Storni SI, Hugo (1980) Catálogo de los jesuitas de la Provincia del Paraguay (Cuenca del Plata) 1585-1768, Roma: Institutum Historicum S.I.

Teschauer, Carlos (1922), Historia do Rio Grande do Sul, Porto Alegre, T. III.

Trelles, Manuel Ricardo (1882), “Maloca misionera”, Revista de la Biblioteca Pública de Buenos Aires, Buenos Aires: Imprenta Europea. 